Review Article

\title{
Power Ultrasonic Additive Manufacturing: Process Parameters, Microstructure, and Mechanical Properties
}

\author{
Abdullahi K. Gujba and Mamoun Medraj \\ Department of Mechanical, Industrial and Aerospace Engineering, Concordia University, \\ 1455 De Maisonneuve Blvd. W. Montreal, H3G 1M8, Quebec City, Quebec, Canada \\ Correspondence should be addressed to Mamoun Medraj; mmedraj@encs.concordia.ca
}

Received 28 October 2019; Accepted 30 January 2020; Published 28 February 2020

Academic Editor: Zhiping Luo

Copyright (c) 2020 Abdullahi K. Gujba and Mamoun Medraj. This is an open access article distributed under the Creative Commons Attribution License, which permits unrestricted use, distribution, and reproduction in any medium, provided the original work is properly cited.

\begin{abstract}
Additive manufacturing (AM) for fabricating 3D metallic parts has recently received considerable attention. Among the emerging AM technologies is ultrasonic additive manufacturing (UAM) or ultrasonic consolidation (UC), which uses ultrasonic vibrations to bond similar or dissimilar materials to produce 3D builds. This technology has several competitive advantages over other AM technologies, which includes fabrication of dissimilar materials and complex shapes, higher deposition rate, and fabrication at lower temperatures, which results in no material transformation during processing. Although UAM process optimization and microstructure have been reported in the literature, there is still lack of standardized and satisfactory understanding of the mechanical properties of UAM builds. This could be attributed to structural defects associated with UAM processing. This article discusses the effects of UAM process parameters on the resulting microstructure and mechanical properties. Special attention is given to hardness, shear strength, tensile strength, fatigue, and creep measurements. Also, pull-out, push-out, and push-pin tests commonly employed to characterize bond quality and strength have been reviewed. Finally, current challenges and drawbacks of the process and potential applications have been addressed.
\end{abstract}

\section{Introduction}

Historically, ultrasonic welding of metals has been in existence since the 1950s for welding battery tabs, and thin foil for packaging application and for electronic wires [1]. Ultrasonic additive manufacturing (UAM) or ultrasonic consolidation (UC) process was invented and patented by Dawn White [2]. In 1999-2000, White founded Solidica Inc. [3] in order to sell commercial UAM machines. UAM or UC is a solid-state technology for joining similar or dissimilar materials (usually metal foils) near room temperature by bonding them together layer by layer with ultrasonic vibrations under pressure to form $3 \mathrm{D}$ as-built parts [4]. The working principle of this technology is simple, and Figure 1 illustrates the UC process and setup components. A typical UAM system consists of a two ultrasonic transducers (frequency up to $20 \mathrm{kHz}$ each) which transmit vibrations to a disk-shaped sonotrode in order to create solid-sate weld.
Figure 2 demonstrates the steps involved in attaining a high-strength bond via UAM. The process begins with laying a metal base plate and pressing a thin metal foil on it $[1,5]$. High-frequency ultrasonic vibrations are applied in order to scrub the mating faces while keeping a constant force [1]. The ultrasonic motion causes shearing, which cleans off the surface oxides via friction to allow direct metal-metal contact. Also, this shearing process leads to generation of dynamic interfacial stresses between the contacting surfaces [2]. Plastic deformation and recrystallization at the bond interface result in a high-strength metallurgical solid-state bond [1]. Kong et al. [6] suggested that the mechanism of this solid-state bonding can be classified into two: First is the volumetric bonding, which is associated with the elastic and plastic deformation due to acoustic and thermal softening [7]. Microstructural analyses have shown that plastic deformation plays an important role in facilitating the onset of bonding $[8,9]$. Second is the surface bonding, which is 


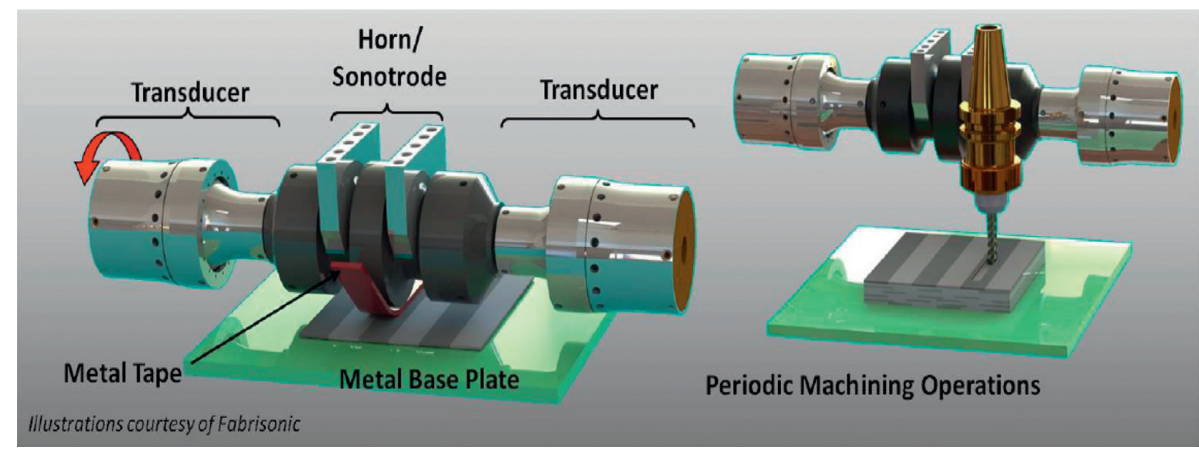

Figure 1: UAM process and components illustration by Fabrisonic $\odot$ [1].

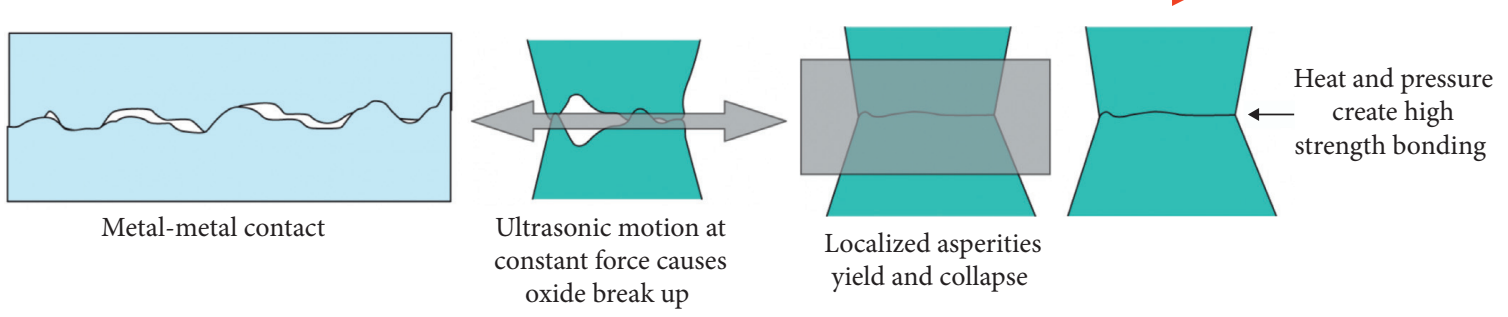

FIGURE 2: Steps in attaining high-strength bonds via ultrasonic consolidation [1].

associated with interfacial friction and shearing that breaks up the oxide layers [10]. UAM operates at temperatures much lower than the melting temperatures of the starting materials, usually $0.3-0.5 \mathrm{Tm}$. Melting is avoided and voids/ defects associated with high temperature are eliminated [11]. With this attribute, bonding of dissimilar materials becomes feasible, and the properties of each building martial are retained. Similar and dissimilar builds via UAM such as AlAl [10, 12-15], Al-Ti [16], Al-NiTi [17], Al-SiC [18, 19], Al with embedded dielectric materials (inks used in printed electronics industry) [20], low carbon steel [21, 22], and Alshape memory alloy (SMA) [23] have been reported in the literature so far.

Similar to other additive manufacturing processes, the UAM process is accompanied with periodic machining in order to obtain the final geometry. However, only a small amount of machining is required since UAM produces a near-net shape build. For this reason, UAM is sometimes referred to as hybrid additive/substantive manufacturing [24]. Compared with the conventional CNC machining, only a little waste or scrap is formed because of machining after UAM. Figure 3 shows the difference between conventional CNC machining, which starts with a large box, and UAM, which starts with a thin metal sheet and ends up with little or no scrap. To compare UAM with other AM techniques, the next section discusses the competitive advantages of UAM over other AM processes.

\section{UAM versus Other AM Technologies}

UAM as a solid-state process commands several advantages over other available AM techniques. For instance, most AM processes require a certain level of material phase transformation starting from feedstock to the near-net shape geometry [3]. This limits the range of materials that can be deposited. Compared to UAM, layer deposition is achieved using solid-state bonding. Metallurgical bonds between layers are achieved ultrasonically without generating molten metal at the interface [3], and this allows for a wide range of similar and dissimilar materials to be deposited. Also, UAM has a higher deposition rate as compared to other AM processes because of the lower heat input per deposited volume and faster heat dissipation $[3,25]$. Due to the solidstate bonding in UAM, residual stresses and distortions are significantly reduced compared to direct metal deposition, which involves liquid-solid transformation. The high residual stresses are as a result of the rapid heating-cooling thermal cycle during processing [26]. In an ideal AM process, the stress field is much more complicated due to the number and pattern of the heat source and heat transfer. For AM parts, high tensile residual stresses are usually on the surface of the metal build, which could affect the mechanical properties. The effect of these stresses could be mitigated via in-process or postprocess methods [26]. In terms of applications, complex geometries such as internal channels and voids can be fabricated using UAM. This has been explored for applications such as 3D channels for microchannel cooling and cooling channels for molds. Also, during UAM processing, the building process can be interrupted and subsequent machining can be performed [24]. This is extremely difficult while using other manufacturing techniques. Another key contrast between UAM and other techniques is the embedment of materials such as optical fibers into metallic components. For instance, embedding $\mathrm{SiC}$ fibers and single-mode (SM) optical fibers into Al3003 and Al6061 matrices has been successfully reported by Li and 


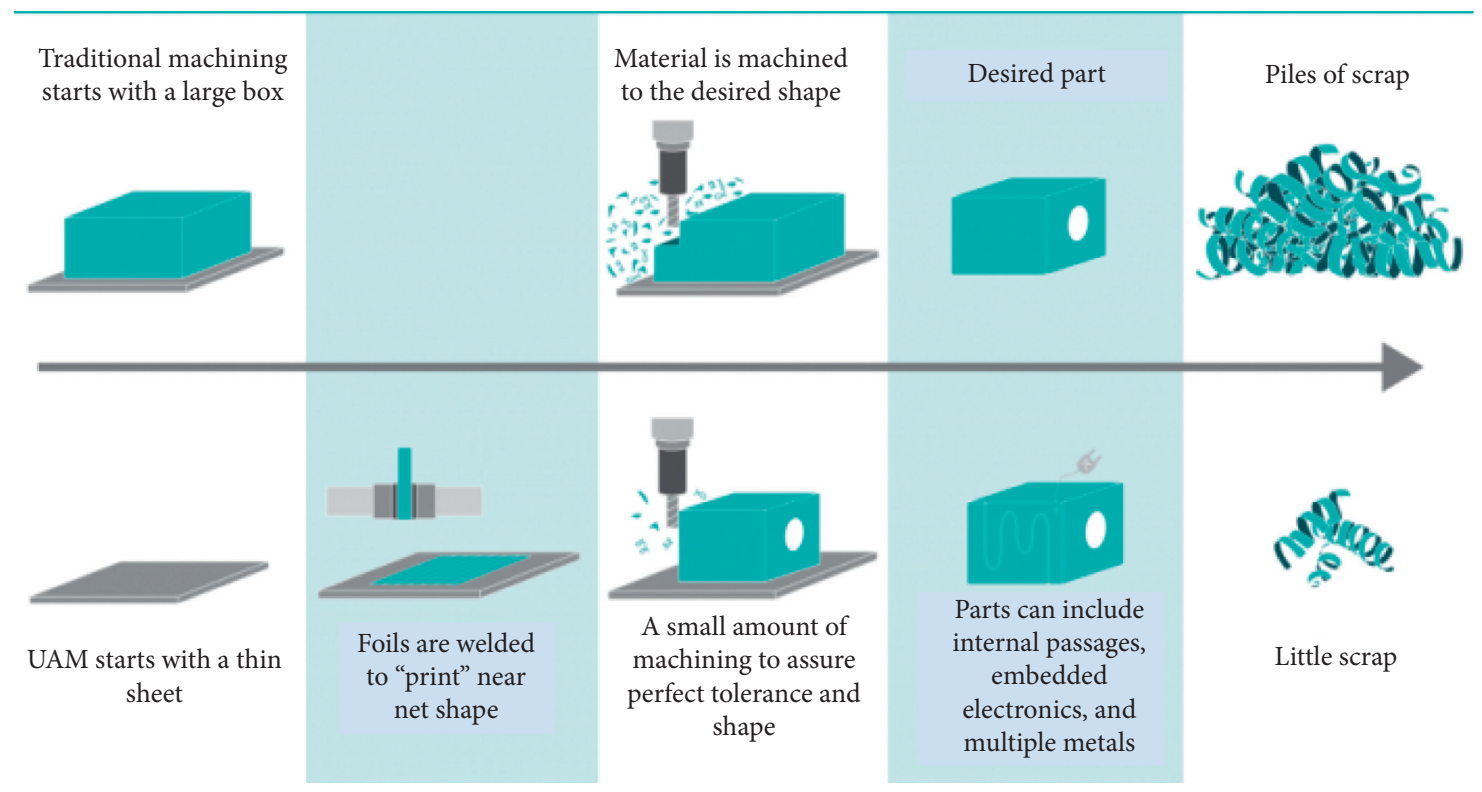

FIgURE 3: Difference between conventional CNC and UAM processes [1].

Soar [27]. This is not possible with other AM techniques because of the high temperature during processing. It is worth noting that achieving these advantages via UAM requires understanding of different process parameters and their impact on resulting microstructures and properties. The next section highlights some of the important UAM process parameters.

\section{UAM Process Parameters}

The formation of high-strength and quality bond during the UC process is dependent on the process parameters employed. Among the most influential process parameters are normal force $(\mathrm{N})$, amplitude $(\mu \mathrm{m})$, speed $(\mathrm{mm} / \mathrm{s})$, and temperature $\left({ }^{\circ} \mathrm{C}\right)$. An important component that influences these process parameters is the sonotrode which comes into direct contact with the materials and provides the necessary energy for bonding [24]. It provides uniform load and vibration to the parts bonded ultrasonically. Sonotrodes are usually made of titanium, aluminum, or steel with varying surface finish intended for different applications. For instance, sonotrode made of steel has an average surface roughness ( $\mathrm{Ra}$ ) of $5.2 \mu \mathrm{m}$ [20] and is used for low-amplitude applications where hardness is required. Titanium is the most used due to the low loss of vibration and high strength, while aluminum, which is usually coated with chrome or nickel, is employed to reduce wear [24]. The most important variable UAM parameters are discussed below.

3.1. Normal Force (N). Normal force, sometimes referred to as "pressure," is the downward force applied by the sonotrode onto the mating surfaces and can range from $100 \mathrm{~N}$ to $9000 \mathrm{~N}$ depending on the build materials. This constant force provides intimate contact between the building materials during processing and facilitates the plastic flow [8]. With the synergy between the force and ultrasonic oscillations, dynamic stresses are generated which are necessary for oxide removal and plastic flow [8]. Friel and Harris [28] stated that the higher the pressure, the larger the bonding area, which translates to a lower void volume. Depending on the material, too high pressures will lead to larger levels of deformation and excessive stresses $[6,29]$. Consequently, too low pressure will cause insufficient deformation and contact between the build materials, thus leading to a weak bond. Therefore, an optimum force (pressure) is necessary for quality bond with no or minimal number of voids.

3.2. Amplitude $(\mu m)$. Amplitude, which could normally range from 10 to $50 \mu \mathrm{m}$, is the sonotrode longitudinal oscillatory displacement which controls the interface thickness, density of the bonded area, and the size of the deformed area [30]. Powers and Jones [31] stated that the amplitude dictates the amount of plastic deformation between the building materials. Also, the higher the amplitude, the higher the energy generated into the building material interface $[14,23,32]$, which translates to better bonding quality and strength. However, extremely high amplitude results in breaking of already formed bonds due to excessive stresses.

3.3. Speed $(\mathrm{m} / \mathrm{s})$. Speed is the sonotrode motion across the workpiece during processing and could range from $1 \mathrm{~mm} / \mathrm{s}$ to $100 \mathrm{~mm} / \mathrm{s}$ [20]. The speed determines the length of time the material under the sonotrode will undergo compression and oscillation [24]. Also, the energy delivered to the workpiece is inversely proportional to the speed employed. For instance, Kong et al. [33] stated that at a given contact force and amplitude, decreasing the speed (from 38.8 to $27.8 \mathrm{~mm} / \mathrm{s}$ ) increased the energy to the build material, which leads to higher levels of strain hardening. However, in another work by Kong et al. [34], they showed lack of sufficient bonding when the speed was increased from 34.5 to $43.5 \mathrm{~mm} / \mathrm{s}$. 
3.4. Temperature $\left({ }^{\circ} \mathrm{C}\right)$. Substrate temperature is another process parameter which could affect the bond quality as reported by various researchers [14, 17, 29, 35, 36]. During processing, the temperature of the substrate/part can be increased from the ambient condition. George and Stucker [37] mentioned that employing a higher temperature during processing results in denser and stronger bonds. This temperature increase is dependent on the build materials, and careful selection is necessary, especially for dissimilar materials. Table 1 summarizes typical process parameters employed for building different materials by various authors. It can be said from Table 1 that the selection of process parameters is dependent on the build material(s). For instance, a lower substrate temperature is selected when building SMA NiTi with aluminum [17], whereas a higher substrate temperature is selected for building similar materials such as 4130 steel [21]. As mentioned previously, the energy transferred to the workpiece is controlled by varying other process parameters as well.

UAM energy applied during processing is related to the quality of bond formed and can be quantified using the linear weld density (LWD) approach [12, 42]. LWD is the length of a particular interface that appears to be bonded divided by the total length of the interface inspected [12], as shown in equation (1). Bonded interface length refers to the actual length, whereas total interface length refers to the apparent length measured.

$$
\% \mathrm{LWD}=\frac{\text { bonded interface length }}{\text { total interface length }} \times 100 \text {. }
$$

In order to have sound bond quality, LWD must be kept as high as possible. Typically, UAM parts have LWD ranging from 45 to $95 \%$ [12]. Lower values are associated with lower UAM energies, which produce weaker bonds [42]. Parameters such as speed, amplitude, substrate temperature, and normal force have been associated with LWD [5]. For instance, Janaki Ram et al. [5] studied the effect of process parameters on the bond formation of $\mathrm{Al} 3003$ during UC. Using design of experiments (DoE), they [5] obtained an optimum combination of parameters based on preliminary experiments, machine setting limits, and available literature data. Four process parameters, varied at four different levels, were considered, as shown in Table 2. Taguchi L16 orthogonal array shown in Table 3 was employed to determine the effect of each process parameter, and a total of 16 experimental runs were carried out.

Based on Taguchi DoE, they [5] maintained one factor as fixed while varying the other three parameters. For instance, for each value of amplitude, three sets of the other parameters (speed, force, and temperature) are used as shown in Tables 2 and 3. However, the \% LWD results were presented in [5] as average of values measured at different parameters as indicated by the empty-square symbol in Figures 4(a) and 4(b). This unfortunately can be misleading because average values are not representative of the data obtained in these experiments, as can be seen in Figures 4(a) through 4(d). In these figures, the actual data for the 16 experiments were obtained from Yang et al. [43]. In our article, statistical analysis was performed and is discussed below. Relying on the average values, Janaki Ram et al. [5] attributed changes in \% LWD to varying a single parameter, such as saying that increasing the amplitude from 10 to $16 \mu \mathrm{m}$ increased the \% LWD. However, this cannot be concluded from the data shown in Figures 4(a)-4(d). Nevertheless, since their work [5] is based on Taguchi DoE, different information can be obtained from the results as discussed below.

Using the available data from [43], the percentage contribution of each process parameter was calculated as shown in Figure 4(e). It can be seen that amplitude had the highest contribution followed by temperature. Force had the least contribution, which is half the contribution of temperature. Also, the mean value of signal-to-noise ratio $(S / N)$ was evaluated. Since higher \% LWD is desirable, larger is better option was selected for this analysis, and the results are presented in Figure 4(f). Similar to the percent contribution, amplitude showed the highest $S / N$ ratio between 30 and $36 \mathrm{~dB}(\Delta=6)$ followed by temperature, which had an $S / N$ ratio between 31 and $36 \mathrm{~dB}(\Delta=5)$. Speed had the least $S /$ $N$ ratio from 32 to $34 \mathrm{~dB}(\Delta=2)$. This means when attributing the changes in \% LWD to any parameter, these average contributions have to be kept in mind. For instance, when the authors [5] mentioned that increasing the substrate temperature increases the LWD, the contribution of amplitude in this increase is much higher than that of temperature. Therefore, it cannot be attributed to the speed only as presented in [5]. The same goes for the other parameters, even for the effect of amplitude because in this case, the effect of changing the other parameters contributes around $60 \%$ in varying \% LWD.

As expected, the resulting microstructure and mechanical properties would be affected by the UAM process parameters. For this reason, a significant part of the literature on UAM paid more attention to optimization of the process parameters $[29,34,40,44]$ and microstructural analyses $[12,22,28,45,46]$ of the as-built part. The microstructural analyses provide substantial information about the bonding mechanism, grain refinement, and defects, which are highlighted in the next section. To date, extensive and universally accepted mechanical properties and characterization procedure of UAM printed parts could not be found in the literature. Even though properties such as micro/nano-hardness, strength (shear and tensile), and fatigue behavior have been reported, more research is still needed in order to fully understand the mechanical properties of UAM builds. This is discussed in more detail in Section 5 of this article.

\section{Microstructure}

Considering the fact that there are no material transformations associated with UAM, one would expect the constituent materials to retain their properties and microstructure. For this reason, most part of the literature regarding microstructure of UAM builds focused on the interface between the bonds. Also, one could argue that inhomogeneity would exist in the microstructure, especially 
TABLE 1: UAM process parameters used by several authors.

\begin{tabular}{|c|c|c|c|c|c|}
\hline Build material & Force $(\mathrm{N})$ & Speed $(\mathrm{mm} / \mathrm{s})$ & Amplitude $(\mu \mathrm{m})$ & Substrate temperature $\left({ }^{\circ} \mathrm{C}\right)$ & Refs. \\
\hline $\mathrm{Al} 2024$ & 2500 & 46 & 24 & 120 & {$[35]$} \\
\hline Al3003 O/Al3003-H18 & 1400 & 42.3 & 19 & 149 & {$[38]$} \\
\hline Al3003-H18/Al1050-H14 & 1600 & 20 & 25 & - & {$[20]$} \\
\hline $\mathrm{Al} 3003 / \mathrm{Al} 3003-\mathrm{H} 18$ & $1450-1900$ & $28-40$ & $10-19$ & 24-149 & {$[5]$} \\
\hline Al3003-H18/Al3003-H14 & $600-1000$ & $18-26$ & $42-64$ & 149 & [14] \\
\hline Al1100-O/CP Ti & 3500 & 25.4 & 41.55 & $200^{\circ} \mathrm{F}$ & [39] \\
\hline $\mathrm{Al} 3003-\mathrm{H} 18 / \mathrm{CP} \mathrm{Ti}$ & $1750-2000$ & $10.58-23.70$ & $16-28$ & $300^{\circ} \mathrm{F}$ & [40] \\
\hline Al6061-H18 & 5000 & 85 & 35 & 75 & [13] \\
\hline $\mathrm{Al} 3003-\mathrm{H} 18$ & 5600 & 35.6 & 26 & - & [41] \\
\hline NiTi/Al6061 & 6000 & 84.6 & 32.76 & 22 & [17] \\
\hline NiTi SMA/Al3003-H18 & $138 \mathrm{kPa}$ & $\leq 34.5$ & $8.4-14.3$ & - & [23] \\
\hline $\mathrm{Cu} / \mathrm{Al} 3003-\mathrm{H} 18$ & 6700 & 30 & 36 & 25 & [36] \\
\hline $\mathrm{SiC} / \mathrm{Al} 3003$ & $1400-2000$ & $25-42$ & $10-20$ & $66-177$ & [29] \\
\hline Al6061-H18 & 5000 & 84.7 & 35 & 75 & [15] \\
\hline 4130 steel & 6000 & 21 & 30.87 & 204 & [21] \\
\hline
\end{tabular}

at the bonds. Thus, to understand the bonding quality and mechanism of UAM builds, microstructural investigation is paramount. This aids in understanding the fundamental processes during UAM. For instance, Fujii et al. [47] observed the microstructures of the unbonded and bonded interfaces of Al6061 build using bright-field TEM, as shown in Figure 5.

Figure 5(a) shows asperities that are in direct physical contact between the top and bottom surfaces of the build materials. These micro-asperities are compressively deformed by applying load (force), which consequently leads to microbond formation as shown in Figure 5(b). During the microbond formation, the asperities are softened and crushed under high-strain-rate deformation due to ultrasonic vibrations [47]. With continuous softening and crushing, significant amounts of microbonds are formed across the interface, as shown in Figure 5(c). Some amount of oxide films are still visible but are dispersed around the interface because of friction and plastic flow. Through the dispersion of oxide films, direct contact between the mating surfaces is achieved, and full metallurgical bonds are formed as shown in Figure 5(d). Finally, they [47] reported that the originally elongated grains were replaced by the newly developed fine equiaxed grains. Sriraman et al. [36] also observed formation of equiaxed grains in the copper build. They [36] showed that the relatively coarse grain size of $25 \mu \mathrm{m}$ in the as-received foils is reduced to a finer and more uniform grain size of 0.3 to $10 \mu \mathrm{m}$. The finer grains occur due to recrystallization and movement of grain boundaries across the interface [36].

The presence of voids at the interface is one of the most widely reported features, and this determines a partially or fully bonded interface. For instance, Hopkins et al. [14] observed voids at the interface of Al3003 build, as shown in Figure 6. They [14] reported that three distinct features were observed at the interface: areas with large voids, areas with small crack-like voids and partial bonding, and areas where there are no observable voids, which are assumed to be fully bonded.

Janaki Ram et al. [5] also classified these voids (defects) observed in Al3003 build into three different morphologies, as shown in Figure 7. These are line defects, parabola-like
TABle 2: Process parameters and levels selected [5].

\begin{tabular}{lccccc}
\hline Parameter & Label & Level 1 & Level 2 & Level 3 & Level 4 \\
\hline Amplitude $(\mu \mathrm{m})$ & $\mathrm{A}$ & 10 & 13 & 16 & 19 \\
Speed $(\mathrm{mm} / \mathrm{s})$ & $\mathrm{B}$ & 28 & 32 & 36 & 40 \\
Force $(\mathrm{N})$ & $\mathrm{C}$ & 1450 & 1600 & 1750 & 1900 \\
Temperature $\left({ }^{\circ} \mathrm{C}\right)$ & $\mathrm{D}$ & 24 & 66 & 107 & 149 \\
\hline
\end{tabular}

Table 3: Taguchi L16 experimental matrix [5].

\begin{tabular}{lllllc}
\hline Run $^{\#}$ & A & B & C & D & \% LWD \\
\hline 1 & 1 & 1 & 1 & 1 & 18 \\
2 & 3 & 4 & 2 & 1 & 55 \\
3 & 4 & 2 & 3 & 1 & 67 \\
4 & 2 & 3 & 4 & 1 & 25 \\
5 & 2 & 4 & 3 & 2 & 32 \\
6 & 4 & 1 & 4 & 2 & 76 \\
7 & 1 & 2 & 2 & 2 & 24 \\
8 & 3 & 3 & 1 & 2 & 55 \\
9 & 2 & 1 & 2 & 3 & 60 \\
10 & 1 & 3 & 3 & 3 & 50 \\
11 & 4 & 4 & 1 & 3 & 36 \\
12 & 3 & 2 & 4 & 3 & 57 \\
13 & 4 & 3 & 2 & 4 & 70 \\
14 & 3 & 1 & 3 & 4 & 90 \\
15 & 2 & 2 & 1 & 4 & 60 \\
16 & 1 & 4 & 4 & 4 & 42 \\
\hline
\end{tabular}

*Average \% LWD from [5].

defects, and point-like defects, which are designated as D1, D2, and D3 in Figure 7. They [5] linked the presence of these defects to the UAM processing parameters. Line defects were observed in specimens having very low \% LWD, deposited using low amplitude and/or normal force. Parabolic defects are associated with the medium or medium-to-high weld density levels, while point defects were observed with specimens with very high weld density levels [5]. Similar observations have been reported on Al6061-H18 [13] and 4130 steel/steel parts [21].

Generally, the presence of these voids (line, point, and parabolic) is associated with the sonotrode that rolls over several layers $[5,12,32,46]$. For instance, the first layer 


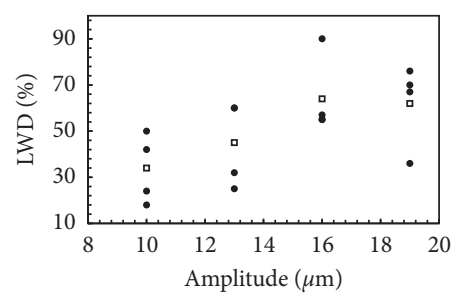

- Original data from [43]

- Average data from [5]

(a)

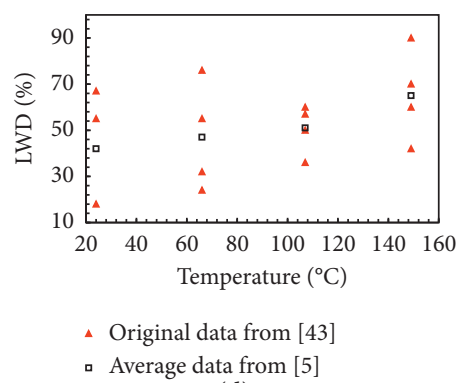

(d)

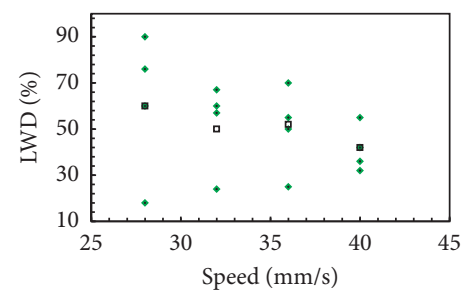

- Original data from [43]

- Average data from [5]

(b)

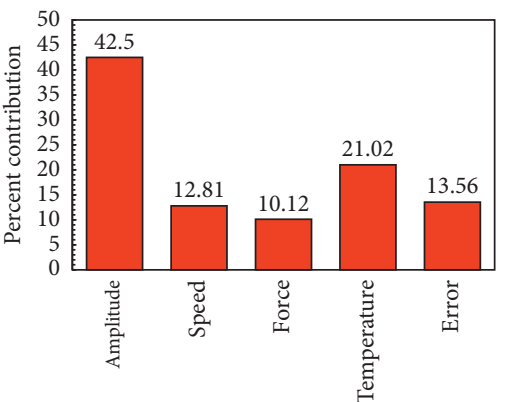

(e)

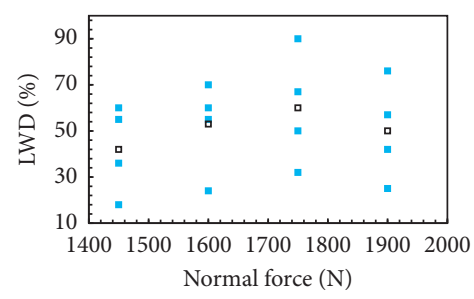

- Original data from [43]

- Average data from [5]

(c)

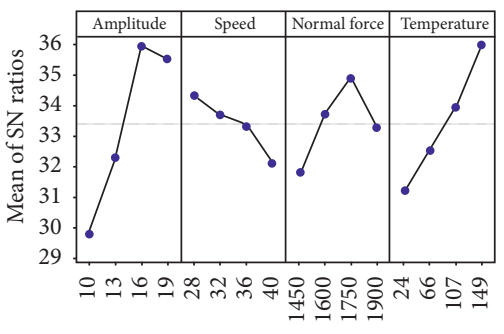

(f)

Figure 4: Effect of (a) amplitude, (b) speed, (c) normal force, and (d) substrate temperature on \% LWD of Al3003 build material. ((a-d) redrawn from [43], (e) and (f) from this work).

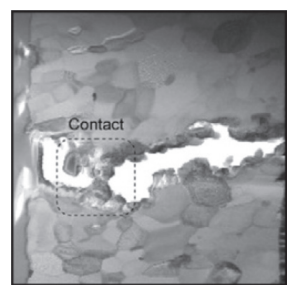

(a)

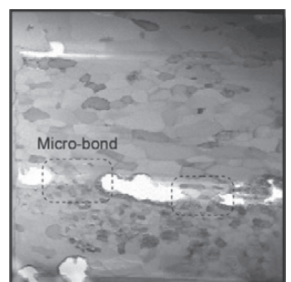

(b)

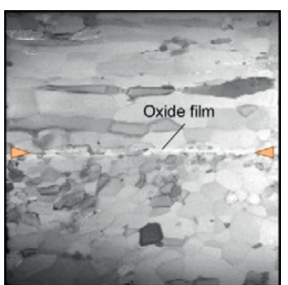

(c)

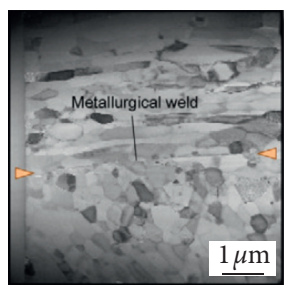

(d)

FIGURE 5: Bright-field TEM images of (a) unbonded region, (b) partially bonded region, (c) bonded region with residual oxide film, and (d) completely bonded region [47].
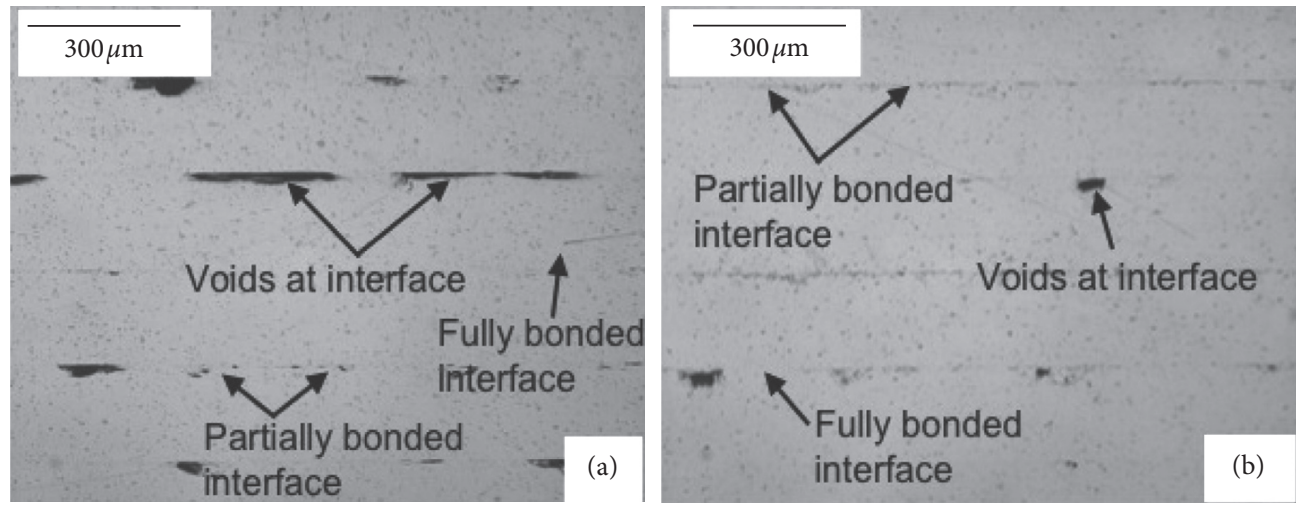

FIGURE 6: Macrographs of Al3003 build showing voids at the interface [14].

bonded on the substrate usually leaves a roughened surface due the sonotrode motion [5]. The next layer to be applied has a relatively flat bottom (smooth surface) which comes in contact with the roughened surface of the first layer. This creates a mismatch between the smooth and rough surfaces and results in weak bonds with many voids [5]. A similar explanation was given by Levy et al. [21] where they attributed the defects to the presence of oxides on the foil 


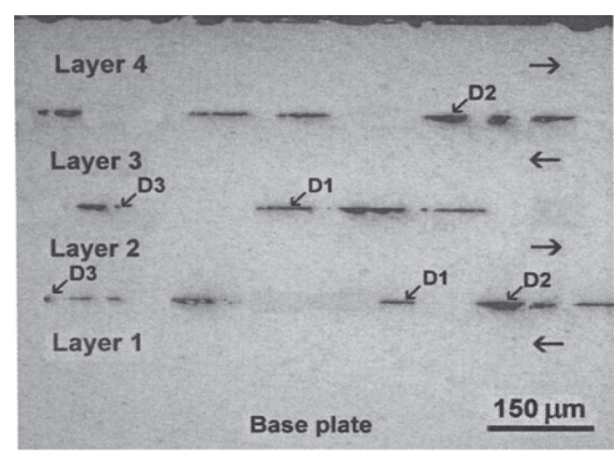

Figure 7: Microstructure of Al3003 showing line (D1), parabolic (D2), and point defects (D3) [5].

surface and the roughened top surface. At this point, one would imagine that UAM builds are not defect free and more work is needed in order to fabricate defect-free builds or, at the very least, mitigate the formation of voids. To tackle the issues of voids during processing, postprocessing, such as heat treatments using spark plasma sintering (SPS) $[11,21,39,48]$ and hot isostatic press (HIP) $[11,21]$, has been employed. For instance, Levy et al. [21] employed both SPS and HIP in order to minimize the multiple defects observed in $4130 \mathrm{steel} / \mathrm{steel}$ build. Figure 8 shows the SEM micrographs of a cross-sectional view of the 4130 steel build before and after SPS. From Figures 8(a) and 8(b), it can be seen that as-built condition had discontinuities and large number of defects. After SPS treatment (Figures 8(c) and 8(d)), the specimens showed relatively small discontinuities and small rounded void. The SPS also showed less voids as compared to the HIP, which had larger discontinuities. This indicates that posttreatments of UAM builds are necessary in order to avoid significant loss of material properties due to the presence of voids. Using other techniques such as microwave sintering could produce interesting results, since microwave has been used successfully to produce fully dense materials similar to SPS [49]. Optimum heat treatment parameters must be selected carefully in order to avoid grain growth near the bonding interface. Also, posttreatment of dissimilar materials could be a challenge at different temperatures, especially if each material reacts differently with temperature. Here, more fundamental studies are needed to address this challenge.

\section{Mechanical Properties}

Since UAM or UC fabricates 3D products by adding thin layers (as thin as $\sim 0.125 \mathrm{~mm}$ ) one on top of the other through joining them using ultrasonic vibration, the mechanical properties of the as-built parts will be influenced by the quality and characteristics of the interface between the layers. The interfacial bonding is usually between metal foils/ tapes [12] where metal-metal contact under pressure results in plastic deformation, dispersion of oxides, and collapse of asperities [21]. For enhanced mechanical properties, a strong continuous interfacial bonding is paramount [21]. Different levels of properties could be achieved by carefully selecting the processing parameters. The variation in mechanical properties of UAM as-built parts is dependent on the materials, building direction, postprocessing treatment, and presence of void/defects. As mentioned in Section 4, defects in UAM as-built parts are usually located at the interface between the layers. Lack of bonding [12] and fusion [50] are internal defects that are classified as the most common imperfections that affect the properties of the build. These defects have detrimental effects on the mechanical properties of the finished parts. They reduce the load-bearing capacity and create stress concentrations in the vicinity of the defect.

Surface finish or roughness, which serves as a preferential site for crack initiation and propagation [51], affects the surface properties of the as-built parts significantly. Obviously, a smooth surface yields better fatigue properties compared to a rough surface $[50,51]$. In additive manufacturing, parts usually suffer from poor surface quality (rough surface), which limits their fatigue behavior/ performance [52]. Building direction is another factor that significantly influences the mechanical properties of the UAM as-built part. Properties such as hardness and strength have been reported along $X-, Y$-directions or transverse/ longitudinal directions [12] and the $Z$-direction (building direction). For instance, the UAM as-built strength is significantly reduced when loaded normal to the $Z$-direction, which is attributed to the presence of defects $[13,53] . X$ - and $Y$-directions have shown relatively similar properties [13], and sometimes these directions are used interchangeably [15]. Producing repeatable and robust joints is still a challenge for UAM [21]. Thus, the need to enhance the mechanical properties of these joints is paramount. Postprocessing (posttreatment) has been found to enhance the mechanical properties and structural homogeneity [21] of UAM asbuilt parts and has received considerable attention $[11,13,39,48,53]$. Postprocessing (treatments) using spark plasma sintering $[11,21,39,48]$, hot isostatic pressing $[11,21]$, and solutionizing and aging [13] have been explored so far. These posttreatments heal the interface defects, improving the mechanical properties [21]. Properties such as hardness, shear and tensile strength, and fatigue of UAM builds are discussed in the following sections.

5.1. Hardness. Hardness is one of the important properties of UAM as-built parts. This property is significantly influenced by the process parameters, postprocessing, and $\mathrm{mi}-$ crostructure (grain refinement). For instance, it is known that fine microstructure is usually associated with an increase in hardness. As mentioned earlier, this is due to plastic deformation encountered during the UAM process, which refines the microstructure across the interface region. For instance, Schick et al. [12] reported the microhardness of as-built UAM Al3003 which was fabricated using both tape (H18, $150 \mu \mathrm{m}$ thick, $25.4 \mathrm{~mm}$ wide) and substrate (H14, more than 12.7-mm-thick plate). Using a 25-g load and a 13$s$ dwell time, the average microhardness of the UAM foils increased almost $15 \%$ from $64.5 \pm 2.7 \mathrm{HV}$ for the original foils to $73.7 \pm 1.9 \mathrm{HV}$ for the as-built. This was attributed to the modified microstructure. Similar observations were mentioned in the work of $\mathrm{Li}$ and Soar [27] where they 

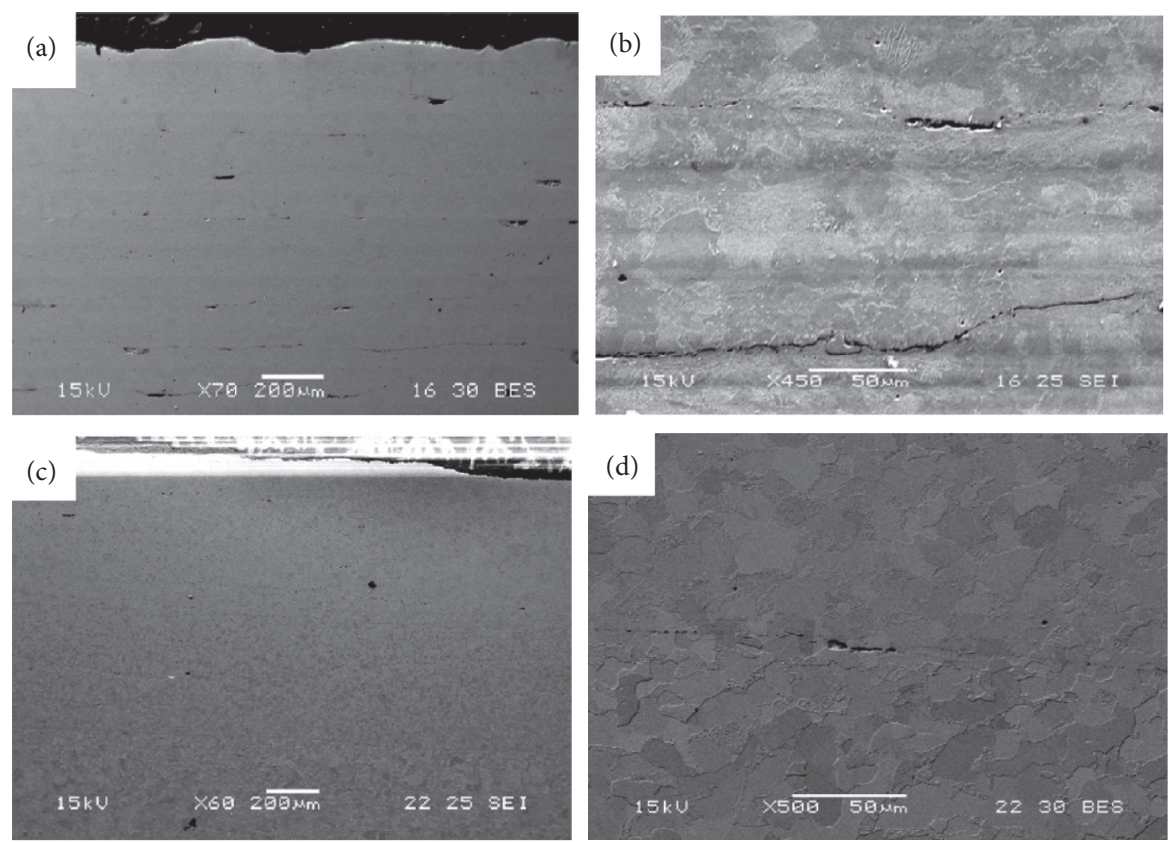

FIGURE 8: SEM micrographs of 4130 specimen before (a, b) and after (c, d) SPS treatments [21].

successfully embedded SiC fibers and single-mode (SM) optical fibers into Al3003 and Al6061 matrices using ultrasonic consolidation. Their [27] results showed that the UC process increased the hardness of alloy matrices, especially at regions close to the fibers. The work-hardening effect obeyed the Hall-Petch relationship for both grains and sub-grains. Li et al. [20] studied the feasibility of embedding electrical materials (inks widely used in the electronics industry) within metal matrices by UAM. To create the metal matrix, a $100 \mu \mathrm{m}$ thick Al3003 was welded on to a $5 \mathrm{~mm}$ thick Al1050-H14. Three different dielectric materials (Commercial inks, LuxPrint ${ }^{\circledR} 8153$ from DuPont ${ }^{\mathrm{TM}}$, 520 Series Soldermask made by Technic, and Imagecure ${ }^{\circledR}$ AQ XV501T-4 of Sunchemical ${ }^{\circledR}$ ) were embedded into UAM-fabricated $\mathrm{Al}$ metal matrices, and the effect of these dielectric materials on Knoop hardness was reported. After printing, they [20] demonstrated Knoop hardnesses of $12.1 \mathrm{HK} / 0.01 \mathrm{~kg}, 23.0 \mathrm{HK} / 0.01 \mathrm{~kg}$, and $27.3 \mathrm{HK} / 0.01 \mathrm{~kg}$ for 8153, XV501T-4, and 520 series dielectric films, respectively. Moreover, they [20] pointed out that varying dielectric thickness had no significant effect on the Knoop hardness. For instance, 8153 dielectric film with thicknesses of $43,45,48,50$, and $54 \mu \mathrm{m}$ showed no significant differences in the Knoop microhardness. It can be said that the variation in thickness (for 8153 dielectric film) is within a small margin; however, thickness in the range of millimeters might show a significant difference.

The effect of postprocessing/treatments on hardness has also been reported in the literature. For instance, Levy et al. [21] studied the suitability of manufacturing low-alloy carbon steel using UAM and the effect of posttreatments on the properties. SPS and HIP posttreatments were conducted after fabrication, and the microhardness of the as-built, SPS, and HIP treated conditions was reported. The as-built showed average hardness of $206 \pm 20 \mathrm{HV}$, and HIP showed hardness of $153 \pm 9 \mathrm{HV}$. SPS showed variation in microhardness along the Z-direction (height) from 159 to $443 \mathrm{HV}$, as shown in Figure 9.

Generally, heat treatment improves hardness, but the HIP showed the opposite trend. This could be due to the long heating time which resulted in significant grain growth, leading to reduced hardness. SPS showed higher hardness, and this can be attributed to the short heating time and preservation of the structure of the material $[54,55]$. The variation in microhardness across the depth of the SPS is due to the specimen top surface contact with the graphite punch, which resulted in carburization [21]. More work is needed in order to optimize the postprocessing conditions, especially for the HIP process. Other heating methods such as microwave heating might be interesting since it also produces relatively dense materials under controlled conditions compared to other conventional techniques [49].

5.2. Peel Test. Peel tests primarily provide measurements of the adhesive strength of tape, glue, or bonded surfaces [12]. Peel test is one of the techniques used in optimizing the process parameters involving joining of tapes. However, these tests do not provide the bulk mechanical properties required for the design of UAM parts. In this case, bulk mechanical properties such as ultimate shear and tensile strength after UAM processing must be accounted for. Despite the known limitations and capabilities of peel testing, researchers still employ this technique to quantitatively assess the bond quality $[6,18,32-34,37]$. For instance, Li and Soar [18] reported the peel strength properties of continuous SiC fibers embedded in an Al6061-O matrix through ultrasonic consolidation at room temperature. They [18] mentioned that after embedding $\geq 0.8 \%$ volume fraction of $\mathrm{SiC}$ in the $\mathrm{Al}$ matrix, the peel strength increased significantly. For instance, at $2.8 \%$ volume fraction of $\mathrm{SiC}$ using 


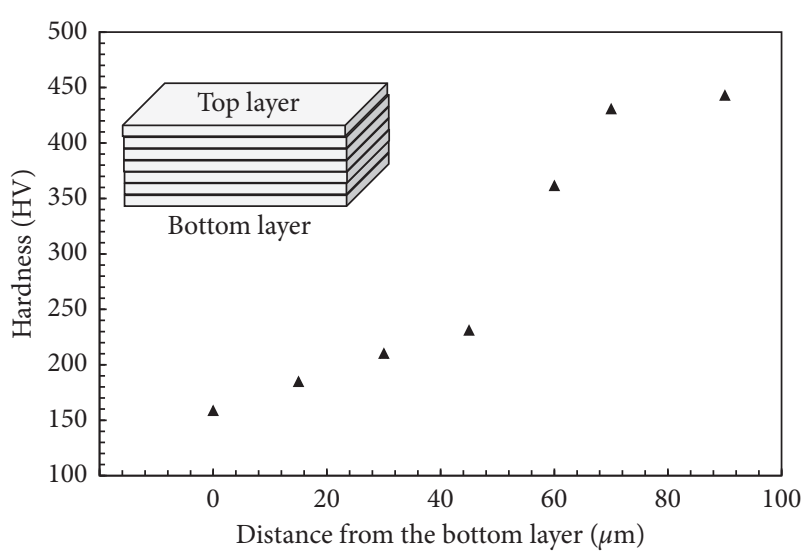

FIGURE 9: Hardness profile of the UAM laminate after the SPS treatment (drawn from [21]).

pressure of $155.8 \mathrm{MPa}$, speed of $34.5 \mathrm{~mm} / \mathrm{s}$, and amplitude of $12.3 \mu \mathrm{m}$, the maximum peel force increased by almost $40 \%$ compared to $0 \%$ volume fraction of SiC. However, they [18] mentioned that there is a threshold volume fraction at specific parameters over which the plastic flow and friction are inadequate to have strong bonds at the foil-to-foil interfaces. Further testing showed that the base metal thickness had no significant influence on the peel strength. Li et al. [20] reported the peel test of an $\mathrm{Al}$ metal matrix embedded with three different dielectric materials (8153, XV501T-4, and 520 series dielectric films). As mentioned in Section 5.1, the 520 series dielectric film had higher hardness than 8153 and XV501T-4 dielectric films. It was found that the higher the hardness of the dielectric material, the higher the peeling loads (higher resistance to deformation). Also, the higher the UAM processing such as load, speed, and amplitude, the higher the peeling load. Amplitude is seen as one of the most significant factors affecting the bonding in UAM $[14,56]$. This observation is in accord with the works of Friel et al. [38], Kong et al. [34], and Sriraman et al. [36] where they observed that the peeling load of Al3003-H18 increased with higher amplitude. This was attributed to the minimal number of voids associated with higher amplitudes during processing as observed by Sojiphan et al. [57]. Peel strength is significantly affected by the presence of voids coming from the sonotrode as pointed out by $\mathrm{Li}$ and Soar [32]. This issue could be overcome by improving the texture of the sonotrode.

The UAM energy produced during processing has an influence on the peel resistances of consolidated parts. Monahgan et al. [42] stated that low-power UAM not only limits the degree of plastic flow but also leads to lower LWD. Here, weaker bonding is produced and peel resistance/ strength is drastically reduced. However, with high-power UAM parameters, high contact pressures and amplitudes that cause plastic flow are produced, increasing the LWD and peel resistance. Although the peel strength test provides firsthand valuable bonding assessment, more information and investigations are required in order to understand the improved deformation resistances at different directions as well as bulk properties such as tensile and shear strengths.
5.3. Pull-Out Test. Accurate evaluation of fiber/matrix interfacial bond strength is still a challenge. One of the methods employed to address this issue is the pull-out test. Typically, the test involves pulling the fiber in order to achieve an initial debonding from the matrix using a microhardness tester [29], synchronizing a force sensor and an acoustic emission (AE) sensor using a dual channel digital oscilloscope attached to the tester [29]. Key features and improvements to this test setup have been proposed by Hehr and Dapino [17]. Figure 10 shows a typical pull-out forcedisplacement curve. Hehr and Dapino [17] studied the pullout strength of NiTi-Al UAM composites. The effect of different surface finish methods of the fibers on the pull-out strength was reported. Oxide, roughened, chemically etched, and mechanically polished surface finished were employed. Their [17] pull-out results showed that the load to failure was similar for all tested surface conditions. More so, the aluminum was observed on the surface of the fiber, which indicates matrix failure rather than interface failure.

Kong et al. [23] also employed the pull-out to characterize the bond strength of ultrasonically embedded shape memory alloy (SMA) fibers in an Al3003 matrix. They [23] showed that process parameters such as amplitude, pressure, and speed had a significant influence on the pull-out performance. For instance, they [23] observed that at higher amplitude, the resistance to pulling reduced, while increasing the pressure did not show any substantial improvement in the pullout force. Furthermore, at a speed of $27.8 \mathrm{~mm} / \mathrm{s}, 6.8 \mu \mathrm{m}$ amplitude had approximately twice the pull-out force compared to 10.4 and $14.3 \mu \mathrm{m}$ amplitudes. Also, comparing $27.8 \mathrm{~mm} / \mathrm{s}$ and $34.5 \mathrm{~mm} / \mathrm{s}$ at the same amplitudes of $6.8,10.4$, and $14.3 \mu \mathrm{m}$, $27.8 \mathrm{~mm} / \mathrm{s}$ had a higher pull-out force. This was attributed to the longer consolidation time, which translates to higher compressive forces being applied to the fiber [23]. The force applied is always constant with time during UAM; hence, one would not expect a higher level of compressive forces applied to the fiber as explained by [23]. Instead, the longer consolidation time associated with lower speed results in more bonding, which increases the pull-out force.

5.4. Push-Out Test. Due to the limitations of the pull-out test in evaluating brittle fibers, Marshall and Oliver [19] proposed the push-out test, which is also a simple test that can be performed using a microhardness tester synchronized with an acoustic emission (AE) sensor. In this method, debonding is caused by pushing the fiber along its axis under the influence of a gradually increasing load. Yang et al. [29] employed the push-out test to evaluate the bond strength between SiC fiber and Al3003 matrix fabricated using UAM. AE signal spikes recorded during the push-out test indicate debonding, and the debonding loads are observed. They [29] showed that debonding loads were random with respect to different parameter variations. The reason for this has not been satisfactorily provided, which indicates more fundamental understanding and research are still needed.

5.5. Push-Pin Test. Another method of evaluating the mechanical performance of bonded or laminated structures is 


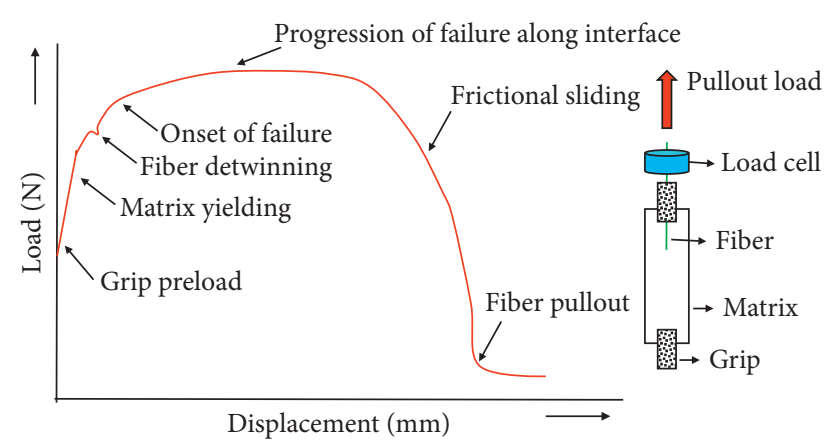

FIGURE 10: Typical pull-out force-displacement curve of UAM asbuilt (redrawn from [17]).

the push-pin technique [39]. This technique proposed by Zhang et al. [58] involves pushing a pin at a specific rate while measuring the load and displacement. The maximum load and the area under the load-displacement curve are used in analyzing the tests [39]. Higher load and larger area under the curve correspond to better push-pin performance. Sridharan et al. [22] reported the push-pin testing performance of Al6061-T6 foils on annealed 4130 steel (Al60614130) and Al-Al (Al6061-6061) builds. Figure 11 shows the load-stroke curves of the push-pin tests for Al6061-4130 steel and Al6061-6061.

It can be seen clearly that the $\mathrm{Al}$-steel showed an average maximum load of $2.85 \mathrm{kN}$, and an area under the curve of $5.15 \mathrm{kN} \cdot \mathrm{mm}$. Al-Al as-built showed an average maximum force of $1.67 \mathrm{kN}$ and an area of $1.53 \mathrm{kN} \cdot \mathrm{mm}$. Hence, the Alsteel showed a higher strength than the Al-Al. This was attributed to the high plastic flow at the interface resulting in oxide removal and asperity collapse, improving the metallurgical bonds and the mechanical properties. Also, one would expect this behavior of Al-steel since steel is stronger than aluminum.

Wolcott et al. [39] reported the delamination strength of Al-Ti UAM build using the push-pin technique. As-built and heat-treated (SPS) specimens were employed, and their results showed that heat treatment enhanced the delamination strength compared to the as-built (untreated). This further indicates the beneficial effect of posttreatments on the mechanical properties of as-built joints.

Despite the considerable efforts made in applying the peel, pull-out, push-out, and push-pin tests, these methods are still debatable on a number of issues, including their universal applicability and accuracy. Standardization of these test methods is required in order to be able to compare different works and fully understand each test applicability and limitations. Combining the data obtained from these tests and from bulk mechanical property investigations could provide more valuable information with regard to bond strength.

5.6. Shear Strength. Shear strength of layered structures or builds is one of the most important studied properties. Special tooling is employed in order to ensure accurate testing within the layered region/section [21]. UAM builds

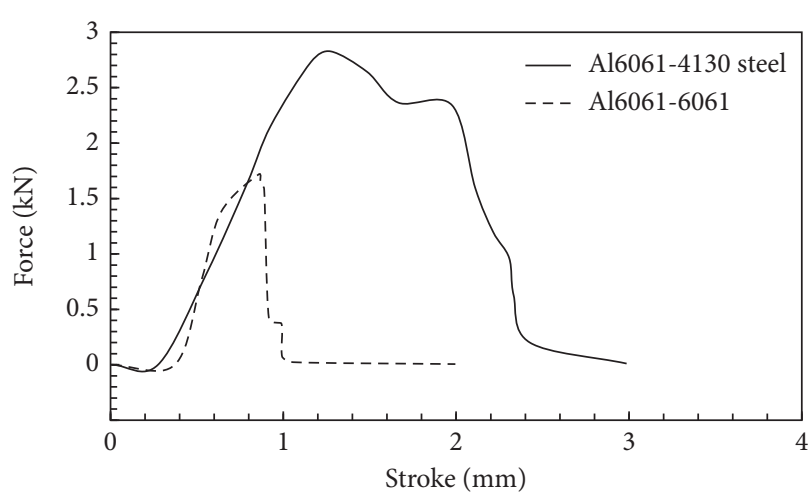

FIGURE 11: Load-stroke curve of the push-pin tests for Al6061-4130 steel and Al6061-6061 build (redrawn from [22]).

usually experience a drop in properties, especially in the building direction $[13,53]$. To improve the quality of welds, especially in the building direction where normal load is applied, posttreatments such as SPS, HIP, and solutionizing and aging have been employed and shown to enhance the shear strength. For instance, Wolcott et al. [39] reported the shear strength of Al-Ti dissimilar material joints fabricated using UAM. As-built and posttreated (SPS) specimens were tested using a 50-kN Lloyd Mechanical Test Frame ${ }^{\circledR}$ where load was applied until failure. Their [39] results showed that the SPS-treated specimen had higher ultimate shear strength $(102.4 \mathrm{MPa})$ than the as-built specimen (46.3 MPa). Fractured surface showed that the as-built had a brittle failure, whereas the SPS had ductile failure, evident from the presence of striation marks. Hopkins et al. [14] observed a similar brittle failure in UAM as-built Al3003-Al3003, which was attributed to the presence of voids and insufficient bonding. Levy et al. [21] studied the shear strength of asbuilt, SPS-, and HIP-treated SAE4130 (low alloy carbon steel) parts. Figure 12 shows the typical load/displacement curves of their shear tests.

It can be seen from Figure 12 that specimens after the SPS posttreatment exhibited shear strength about two-fold higher than that of the as-printed one (maximum load of $4921 \mathrm{~N}$ versus $1690 \mathrm{~N}$ ). The as-printed specimens delaminated and some layers were bent, as shown in Figure 12. From Figure 12, SPS and HIP showed higher resistance to shear than the as-printed condition. Comparing SPS and HIP, SPS had higher resistance than HIP (maximum load of $4921 \mathrm{~N}$ for SPS versus $3727 \mathrm{~N}$ for HIP (Figure 12)). This was attributed to the microstructure where SPS showed only small discontinuity as compared to the as-printed and HIP conditions [21]. For this reason, the SPS remained intact despite some noticeable deformations (Figure 12). This could also be attributed to the inherent nature of the SPS technique, which is known for fabricating highly dense materials with little or no voids $[54,55,59]$. More investigation is needed to determine the failure mechanisms and optimal postprocessing conditions. The interfacial shear strength of a metal matrix composite fabricated via UAM has recently received considerable attention [17,60]. For instance, Hehr and Dapino [17] reported the interfacial shear strength behavior of NiTi-Al matrix composites with 


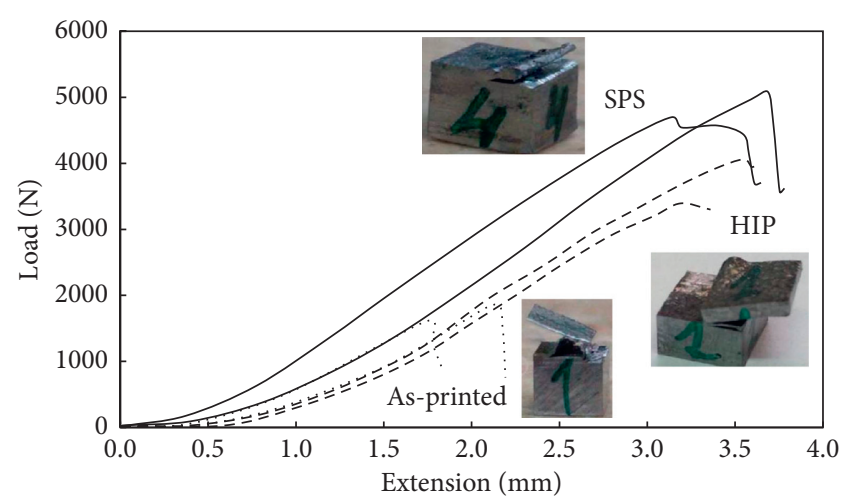

Figure 12: Shear test load/displacement curves and specimens after shear testing (adopted from [21]).

different fiber surface finishes, which include oxide, roughened, etched, and mechanically polished surfaces. For all tested conditions, their [17] results showed that the matrix yielded prior to the interface breaking due to the adhered aluminum. The average shear stress was near or above the ultimate shear strength of the aluminum tapes utilized in the UAM process. For all surface conditions, the matrix was the weakest point in the composite. From the work presented by Hehr and Dapino [17], information addressing the change in bond mechanisms due to the different surface conditions was not discussed. Hence, this needs further investigation. Another issue worth exploring is studying the effect of compressive residual stress on the shear strength of UAM builds. This could not be found in the literature.

5.7. Tensile Strength. Similar to shear strength tests, tensile tests also provide valuable mechanical properties of as-built parts. In the literature, monotonic tensile properties are one of the most commonly evaluated and reported properties of AM parts [50]. For UAM builds, tensile loading is usually applied normal to the interfaces $[13,15]$, as illustrated in Figure 13.

The direction of loading with respect to the building direction has a significant effect on the observed properties. Sridharan et al. [15] reported tensile tests of UAM builds from Al6061-H18 tapes tested at different directions. Tensile dog-bone specimens were machined in three directions: $X$ direction along the travel of the sonotrode, $Y$-direction along the sonotrode vibration, and $Z$-direction along the build where the load is applied normal to the interfaces, as shown in Figure 14. Figure 14 also shows the typical tensile test samples cut from the build.

Five specimens were tested for each direction, and the results were compared with bulk commercial wrought alloy. Directions $X$ and $Y$ are considered the same; hence, they are used interchangeably in [15]. Figure 15 shows the engineering stress-strain curves for the specimens. It can be seen from Figure 15 that the UAM part loaded in the $X$ - and $Y$ directions had lower strength and ductility than the wrought alloy. Also, the specimens loaded along the $Z$-axis showed a significant decrease in the strength level as compared to those along $X$ - and $Y$-directions and wrought alloy. In

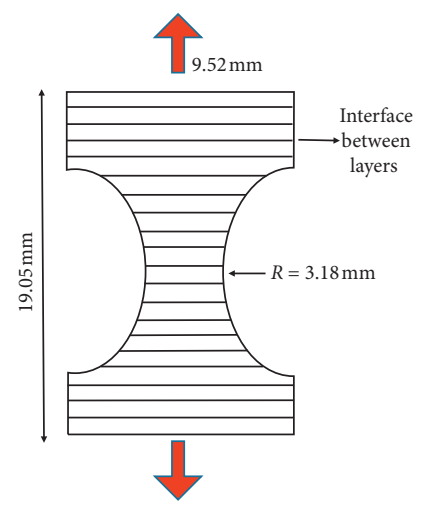

FIgURE 13: Illustration of tensile loading with respect to the interface (redrawn from [14]).

testing along the $Z$-direction (normal to the interfaces), the samples failed by de-bonding of the tapes without significant elongation [15]. The $Z$-direction showed almost zero ductility and resulted in a brittle failure, as shown in Figure 15. This is due to the presence of defects or lack of complete bonding after UAM. Hopkins et al. [14] reported the transverse tensile strength of UAM as-built Al3003-H18 (tape)/Al3003-H14 (base plate). Specimens were axially loaded at $0.127 \mathrm{~mm} / \mathrm{s}$ until failure, while the force and hydraulic ram displacement were recorded. Their [14] graphs showed a linear force-displacement relationship, which indicates that the specimens failed in an elastic brittle mode. Also, specimens with higher strength showed greater displacements, which implies that there were a greater number of localized microscale areas that underwent ductile failure [14]. The brittle failure observed in [14] is in accord with the findings in $[13,15]$. For the brittle failure, a sharp drop in the stress-strain curve is expected after reaching the maximum load. No satisfactory explanation for this behavior was offered by the authors [15]. Perhaps, this behavior could be due to the variation in bond quality across the layer. Detailed fractography is needed in order to understand the failure modes of the build with respect to the different directions.

As mentioned in Section 3, posttreatments of UAM or $\mathrm{UC}$ as-built are employed in order to enhance the mechanical properties of the bond, especially in the $Z$-direction (building direction) $[13,53]$. Gussev et al. [13] studied the solutionizing and aging processing in order to enhance the tensile strength of UAM as-built Al6061-H18 bond at different temperatures. First, the specimens were annealed at $180^{\circ} \mathrm{C}$ for $8 \mathrm{~h}$ in order to restore the $\mathrm{Mg}_{2} \mathrm{Si}$ strengthening precipitate since Al6061-H18 is a precipitation-strengthened alloy. This process is expected to improve the bond properties. Second, the specimens were annealed at $330^{\circ} \mathrm{C}$ for $1 \mathrm{~h}$ in order to recrystallize the grains at the interface, and finally, the specimens were solutionized at $580^{\circ} \mathrm{C}$ for $1 \mathrm{~h}$, quenched in water, and aged at $180^{\circ} \mathrm{C}$ for $8 \mathrm{~h}$. Figure 16 shows the engineering stress versus displacement curves for the build and reference at different heat-treated conditions. It can be seen that properties in the $Z$-direction improved after each heat-treated condition. However, at $330^{\circ} \mathrm{C}-1 \mathrm{~h}$, there was a decrease in the properties in the $X$ - and $Y$-directions including the reference. No specific explanation was given for 


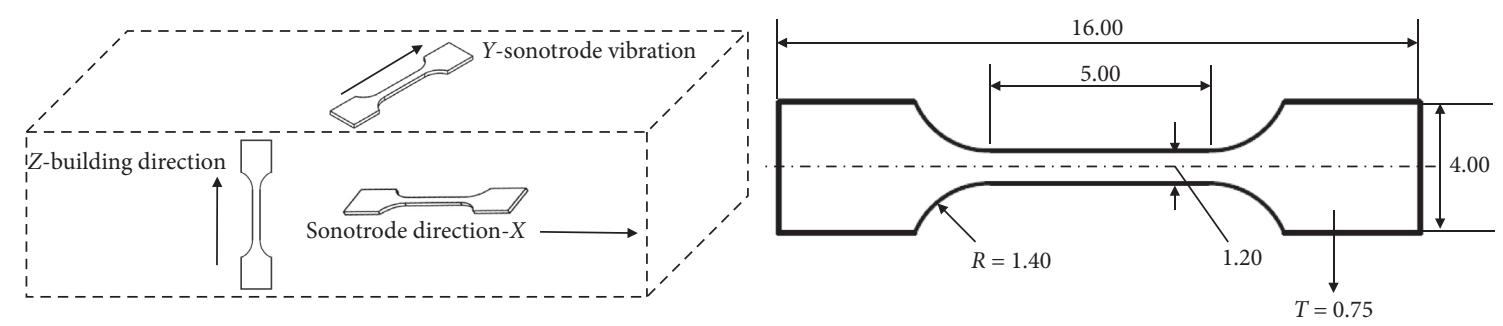

FIGURE 14: Schematic showing the sample extraction for mechanical testing and the dimensions of the tensile test samples (redrawn from [15]).

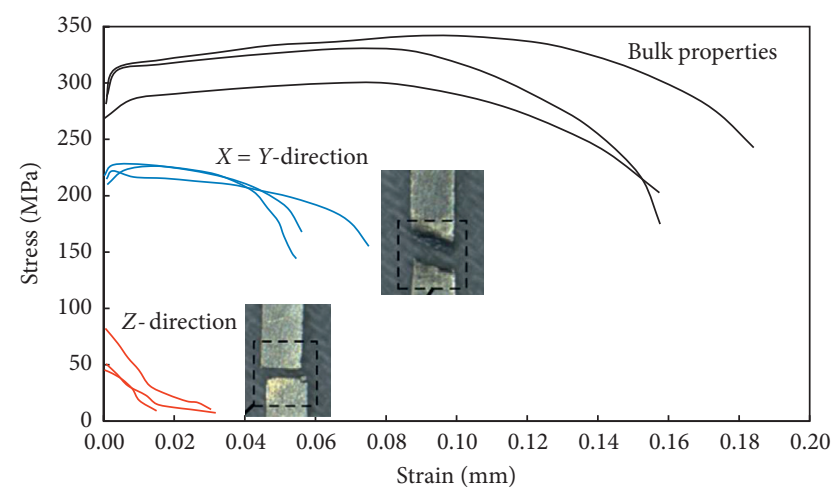

FIGURE 15: Typical engineering tensile curves for the UAM-produced specimens in comparison with bulk commercial alloy (adopted from [15]).

this trend, but this could be due to the interactions between the solute atoms and dislocation, which is dependent on the temperature and strain rate [61]. For $180^{\circ} \mathrm{C}-8 \mathrm{~h}$, the average tensile strength was doubled. This was attributed to the synergic effects of precipitation, reduction in dislocation density, and mild grain coarsening [61]. Finally, for $580^{\circ} \mathrm{C}-1 \mathrm{~h} / 180^{\circ} \mathrm{C}-8 \mathrm{~h}$ treatment, tensile strength was significantly enhanced and the properties in the $X$ - and $Y$-directions were comparable to the reference specimen. This trend was attributed to the significant grain refinement across the interfaces and, consequently, improving the properties. Despite the efforts made in postprocessing of UAM builds, more studies are still needed in order to optimize the heat treatment parameters. For instance, issues of overaging (grain growth) could be detrimental to the mechanical properties of the builds. Hence, more investigations are still needed in this regard.

5.8. Fatigue. The fatigue behavior of UAM-fabricated structures or parts is very important in order to determine potential or estimated lifetime in cyclic loading conditions. While studies of fatigue life of additive manufactured parts have been widely reported for other AM techniques [62-70], there are still no adequate and substantial reports on the fatigue life performance of UAM parts. Most of the UAM reports have concentrated on optimizing processing parameters $[14,29,34,40,44]$, microstructure $[12,22,28,41,45,46]$, interfacial bonding shear $[17,48]$ and tensile strength [13-15], and hardness $[10,12,16,20,27]$. Moreover, tests such as tensile and shear strength might provide more adequate indication/ information of the properties at the interface than fatigue testing. For UAM builds, it is expected that the laminated or layered structure would have different fatigue and fracture mechanisms as compared to monolithic alloy [35]. However, there has been few attempts aimed at investigating the fatigue behavior of UAM as-built aluminum alloys Al2024 [35, 71] and Al3003-H18 [72]. He et al. [35] studied the fatigue of as-built Al2024 made from foils compared with the monolithic alloy. The static three-point load bending fatigue tests were conducted at two stress levels: the maximum stresses were $89 \%$ and $70 \%$ of the tensile strength for $R=0.1$ ( $R$ is the stress ratio employed in fatigue testing, which is the minimum peak stress divided by the maximum peak stress). The fatigue test data are presented in Table 4. From Table 4, L1-L3 and L4-L6 represent results of Al$\mathrm{Al}$ specimens at low and high stress levels, respectively. S1-S3 represent results at high stress levels for $\mathrm{Al}$ specimen, which is higher $(\sim 30 \mathrm{MPa})$ than the stress levels used for L4-L6. It can be seen from the table that the fatigue life of $\mathrm{Al}-\mathrm{Al}$ increased with deceasing applied stress. At high stress level (89\%), both $\mathrm{Al}-\mathrm{Al}$ and $\mathrm{Al}$ specimens had comparable fatigue life.

Wolcott and Dapino [72] reported the transverse tensile fatigue tests of the Al3003-H18 block. Their [72] stressnumber of cycles (S-N) curve was relatively flat, and a stress threshold of $50 \%$ of the ultimate transverse tensile strength exists below which failure does not occur during $3.75 \times 10^{7}$ cycles. They [72] mentioned that their reported preliminary fatigue data are only a prediction. It can be said that UAM is still at the developing stage and much still has to be done to generate fatigue life data for UAM as-built parts. Generally, fatigue life data of additive manufactured parts have been reported to have significant scatter due to the presence of defects [50]. For instance, surface roughness is one of the factors that limits the fatigue performance of AM parts [50]. Several considerations and factors must be addressed when testing the fatigue life of UAM parts. The effect of defects (voids), building direction, residual stresses, surface roughness, postprocessing, and, most importantly, the bonding quality on the fatigue life must be accounted for. Process parameter optimization and fatigue failure analysis are crucial to understand and predict fatigue life of these parts.

Applying mechanical surface treatment is one of the most influential posttreatments that have a significant effect on the fatigue properties. Mechanical surface treatments plastically deform the surface and induce strain hardening. Deep levels of compressive residual stresses are induced while improving the surface and subsurface properties. The induced stresses retard crack initiation and propagation, 

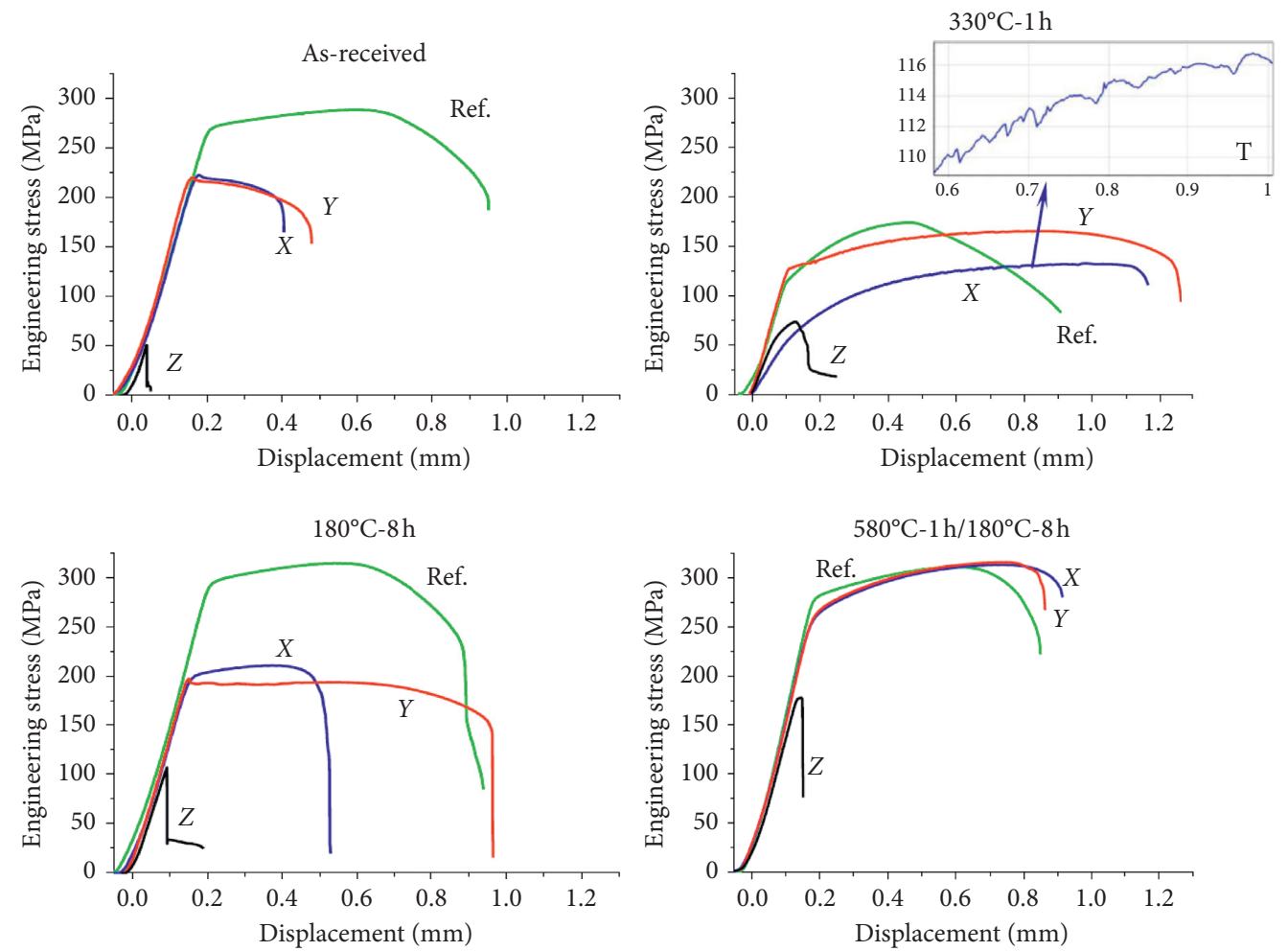

FIGURE 16: Engineering stress versus displacement curves illustrating the effect of annealing on the mechanical behavior of the UAM Al6061 [13].

Table 4: Fatigue test data for $\mathrm{Al}-\mathrm{Al}$ and $\mathrm{Al}$ specimens [35].

\begin{tabular}{lcccc}
\hline Specimen & $\begin{array}{c}\sigma_{n} \\
(\mathrm{MPa})\end{array}$ & $n(\%)$ & $\begin{array}{c}\text { Fatigue } \\
\text { life }\left(N_{f}\right)\end{array}$ & $\begin{array}{c}\text { Average fatigue } \\
\text { life }\left(N_{f}\right)\end{array}$ \\
\hline L1 & 289.04 & & $4.72 \times 10^{4}$ & \\
L2 & 289.04 & 70 & $6.25 \times 10^{4}$ & $4.72 \times 10^{4}$ \\
L3 & 289.04 & & $5.40 \times 10^{4}$ & \\
L4 & 367.50 & & $1.87 \times 10^{4}$ & \\
L5 & 367.50 & 89 & $1.81 \times 10^{4}$ & $1.66 \times 10^{4}$ \\
L6 & 367.50 & & $1.30 \times 10^{4}$ & \\
S1 & 399.84 & & $1.39 \times 10^{4}$ & \\
S2 & 399.84 & 89 & $1.54 \times 10^{4}$ & $1.57 \times 10^{4}$ \\
S3 & 399.84 & & $1.78 \times 10^{4}$ & \\
\hline
\end{tabular}

$\sigma_{n}$ represents the maximum stress level applied on the nominal dangerous cross-section; $n$ represents the ratio of maximum stress applied in the fatigue test to tensile strength.

which translates to improved fatigue properties [51]. For instance, laser shock peening (LSP) [73], shot peening (SP) [74], ultrasonic impact peening (UIP) [75], ultrasonic nanocrystalline surface modification (UNSM) [76], and low plasticity burnishing (LPB) [77] are all mechanical surface treatments that have shown enhanced fatigue properties of components. For more details, Gujba and Medraj [51] reviewed the laser peening process and its impact on material properties in comparison with SP and UIP. It is worth noting that the aforementioned mechanical surface treatments not only induce deep residual stresses but also have varying levels of strain hardening [78]. Hence, the choice of treatment must be made according to the desired properties and application. So far, none of these treatments have been explored with regard to enhancing the properties of UAM builds. Addressing this research gap is paramount and could provide valuable directions into studying the fatigue life of UAM builds. Another factor that must be considered during fatigue life testing is surface finish/roughness of UAM builds. As mentioned in Section 5, surface finish or roughness significantly affects the surface properties, which could limit the fatigue performance. For better fatigue performance, smooth surface finish must be produced either during fabrication or after fabrication. Interestingly, some of the mechanical surface treatments such as UNSM and LPB produce high-quality surface finish which could enhance the fatigue performance. The high-quality surface combined with the induced compressive residual stresses could provide enhanced fatigue performance. This investigation needs considerable attention, and process parameters must be carefully selected.

5.9. Creep. Similar to fatigue, creep behavior of other AM asbuilt parts have been reported [77, 79-83]. However, literature works on understanding the creep behavior of UAM parts could not be found. Microstructural defects are one of the factors that could limit the creep behavior of materials. Other factors that limit the creep behavior of UAM parts are complexity of the creep test in selecting the test temperatures and applied stresses [50]. Most of the builds via UAM are for low temperature applications. For instance, most materials fabricated by UAM are Al-based alloys, and this could be the reason why the creep behavior of these materials has not 
received considerable interests. However, it will be interesting to build materials such as IN718 [79, 80, 83] and IN738LC [81, 82] and investigate their creep behavior since these are for high-temperature applications. In this case, careful selection of creep test parameters is paramount, especially for dissimilar materials.

\section{Challenges and Future Perspectives}

Despite the need to understand the mechanical properties of AM as-built parts, there is still the challenge of directly comparing the properties of materials fabricated by different AM techniques. This is due to the many processing parameters, type of material fabricated, application, and presence of different types and quantity of defects, as well as the limitations associated with various AM techniques. For instance, UAM has shown great potential in fabricating metallic and metal-matrix composite parts, but the process has been limited by a lack of wide range of applications such as high-temperature applications. Significant efforts $[12,17,22,28,45,46,48]$ have been made to understand the interface characteristics. However, eliminating interfacial defects is still a challenge encountered in UAM builds even though posttreatments have shown promising results. Comparing the works of different research groups is still a challenge. This is largely due to the lack of standardized and acceptable mechanical property evaluation procedures for comparative studies [50]. More work is still needed in order to address the overwhelming challenges of understanding the mechanical properties of AM parts. For comparative studies, standardized testing procedures are needed.

In spite of the aforementioned challenges that need to be addressed, UAM technology has been used successfully for different industrial applications. For instance, fabricating heat exchangers with complex internal geometries using high thermally conductive metals has been a challenge. However, Fabrisonic ${ }^{\circledR}$ has successfully built copper and aluminum heat exchangers using UAM. This product has passed rigorous NASA qualifications, such as thermal, vibration, and burst tests [1]. Fabrisonic ${ }^{\circledR}$ has also built thermal management devices with channel size ranging from microscale $(250 \mu \mathrm{m})$ to macroscale $(12.7 \mathrm{~mm})$ for aerospace applications. Building layers of tantalum, molybdenum, and titanium using UAM for radiation shielding in structural panels has also been achieved. Here, one could see that UAM has potentials in various industries such as electronics, aerospace, and power generation. This is due to the ability of the technology to produce complex geometries using similar or dissimilar materials at relatively low fabrication temperatures.

\section{Summary}

UAM or UC process has received considerable attention due to advantages in fabricating $3 \mathrm{D}$ builds using similar and dissimilar materials. Fabrication of 3D parts is achieved at a relatively low temperature compared to other AM technologies. This allows for delicate components such as electronics to be embedded into solid parts. For instance, microprocessors, telemetry, and sensors have been successfully embedded using UAM. Since only a mild level of heating is attained during processing, build material does not experience changes in phase. In other words, initial material properties are retained in the final constituent material properties. Defects are common features observed at the interfacial bonds that affect the properties significantly. However, postprocessing treatments, such as HIP and SPS treatments, have been shown to enhance the properties of the bond. While significant works on process optimization and microstructure of interfacial bonds have been reported, extensive work with respect to mechanical properties is still limited. This is largely due to the lack of standardized testing procedures and limited applications. For instance, fatigue testing and creep properties of UAM builds are still lacking. In conclusion, it is becoming clear that more work is still needed to standardize test procedures that would allow for comparative studies with other technologies and help in realizing UAM potentials. The future of UAM is highly dependent on various industrial applications where other AM technologies fall short. For instance, UAM has shown significant progress in fabricating heat exchangers with complex geometries through integrating dissimilar metals, benefiting from their various physical and mechanical attributes.

\section{Conflicts of Interest}

The authors declare no conflicts of interest.

\section{Acknowledgments}

The authors gratefully acknowledge the financial support provided by Concordia University, Montreal, Canada, through the Horizon Postdoctoral Fellowship and Natural Sciences and Engineering Research Council (NSERC) of Canada.

\section{References}

[1] Fabrisonic, 3D Metal Printing without Melting, Fabrisonic, Columbus, OH, USA, 2019, https://fabrisonic.com/ ultrasonic-additive-manufacturing-overview/.

[2] D. R. White, "Ultrasonic consolidation of aluminum tooling," Advanced Materials Processing, vol. 161, pp. 64-65, 2003.

[3] D. R. White, "Ultrasonic consolidation: status report on development of solid state net shape processing for direct manufacturing," Report No. RTO-MP-AVT-139, pp. 1-66, Defense Technical Information Center, Richmond, VA, USA, 2006.

[4] A. Hehr and M. J. Dapino, "Dynamics of ultrasonic additive manufacturing," Ultrasonics, vol. 73, pp. 49-66, 2017.

[5] G. D. Janaki Ram, Y. Yang, and B. E. Stucker, "Effect of process parameters on bond formation during ultrasonic consolidation of aluminum alloy 3003," Journal of Manufacturing Systems, vol. 25, no. 3, pp. 221-238, 2006.

[6] C. Y. Kong, R. C. Soar, and P. M. Dickens, "A model for weld strength in ultrasonically consolidated components Proceeding of the institution of mechanical engineering, Part C," Proceedings of the Institution of Mechanical Engineers, Part C: Journal of Mechanical Engineering Science, vol. 219, no. 1, pp. 83-91, 2005. 
[7] G. S. Kelly, S. G. Advani, J. W. Gillespie, and T. A. Bogetti, “A model to characterize acoustic softening during ultrasonic consolidation," Journal of Materials Processing Technology, vol. 213, no. 11, pp. 1835-1845, 2013.

[8] Y. Yang, G. D. Janaki Ram, and B. E. Stucker, "Bond formation and fiber embedment during ultrasonic consolidation," Journal of Materials Processing Technology, vol. 209, no. 10, pp. 4915-4924, 2009.

[9] D. Bakavos and P. B. Prangnell, "Mechanisms of joint and microstructure formation in high power ultrasonic spot welding 6111 aluminium automotive sheet," Materials Science and Engineering: A, vol. 527, no. 23, pp. 6320-6334, 2010.

[10] G. S. Kelly, M. S. Just, S. G. Advani, and J. W. Gillespie, "Energy and bond strength development during ultrasonic consolidation," Journal of Materials Processing Technology, vol. 214, no. 8, pp. 1665-1672, 2014.

[11] A. Miriyev, S. Kalabukhov, and N. Frage, "Ultrasonic additive manufacturing of dissimilar material systems: method, postprocessing and properties," in Proceedings of the Fraunhofer Direct Digital Manufactruing Conference (DDMC2016), Berlin, Germany, March 2016.

[12] D. E. Schick, R. Hahnlen, and R. Dehoff, "Microstructural characterization of bonding interfaces in aluminum 3003 blocks fabricated by ultrasonic additive manufacturing," Welding Journal, vol. 89, no. 5, pp. 105-115, 2010.

[13] M. N. Gussev, N. Sridharan, M. Norfolk, K. A. Terrani, and S. S. Babu, "Effect of post weld heat treatment on the 6061 aluminum alloy produced by ultrasonic additive manufacturing," Materials Science and Engineering: A, vol. 684, pp. 606-616, 2017.

[14] C. D. Hopkins, P. J. Wolcott, M. J. Dapino, A. G. Truog, S. S. babu, and S. A. Fernandez, "Optimizing ultrasonic additive manufactured Al3003 properties with statistical modeling," Journal of Engineering Materials and Technology, vol. 134, no. 1, Article ID 011004, 2012.

[15] N. Sridharan, M. Gussev, R. Seibert et al., "Rationalization of anisotropic mechanical properties of Al-6061 fabricated using ultrasonic additive manufacturing," Acta Materialia, vol. 117, pp. 228-237, 2016.

[16] C. Q. Zhang, J. D. Robson, and P. B. Prangnell, "Dissimilar ultrasonic spot welding of aerospace aluminum alloy AA2139 to titanium alloy TiAl6V4," Journal of Materials Processing Technology, vol. 231, pp. 382-388, 2016.

[17] A. Hehr and M. J. Dapino, "Interfacial shear strength estimates of NiTi-Al matrix composites fabricated via ultrasonic additive manufacturing," Composites Part B: Engineering, vol. 77, pp. 199-208, 2015.

[18] D. Li and R. C. Soar, "Characterization of process for embedding $\mathrm{SiC}$ fibers in $\mathrm{Al}$ 6061-O matrix through ultrasonic consolidation," Journal of Engineering Materials and Technology, vol. 131, no. 2, Article ID 021016, 2009.

[19] D. B. Marshall and W. C. Oliver, "Measurement of interfacial mechanical properties in fiber-reinforced ceramic composites," Journal of the American Ceramic Society, vol. 70, no. 8, pp. 542-548, 1987.

[20] J. Li, T. Monaghan, S. Masurtschak, A. Bournias-Varotsis, R. J. Friel, and R. A. Harris, "Exploring the mechanical strength of additively manufactured metal structures with embedded electrical materials," Materials Science and Engineering: A, vol. 639, pp. 474-481, 2015.

[21] A. Levy, A. Miriyev, N. Sridharan et al., "Ultrasonic additive manufacturing of steel: method, post-processing treatments and properties," Journal of Materials Processing Technology, vol. 256, pp. 183-189, 2018.
[22] N. Sridharan, P. Wolcott, M. Dapino, and S. S. Babu, "Microstructure and mechanical property characterisation of aluminium-steel joints fabricated using ultrasonic additive manufacturing," Science and Technology of Welding and Joining, vol. 22, no. 5, pp. 373-380, 2017.

[23] C. Y. Kong, R. C. Soar, and P. M. Dickens, "Ultrasonic consolidation for embedding SMA fibres within aluminium matrices," Composite Structures, vol. 66, no. 1-4, pp. 421-427, 2004.

[24] R. J. Friel, "Power ultrasonics for additive manufacturing and consolidating of materials," in Power Ultrasonics: Applications of High-Intensity Ultrasound, pp. 313-315, Woodhead Publishing, Cambridge, UK, 2015.

[25] A. A. Ward, Y. Zhang, and Z. C. Cordero, "Junction growth in ultrasonic spot welding and ultrasonic additive manufacturing," Acta Materialia, vol. 158, pp. 393-406, 2018.

[26] C. Li, Z. Y. Liu, and X. Y. Fang, "Residual stress metal additive additive manufacturing," in in Proceedings of the 4th CIRP Conference on Surface Integrity, pp. 348-353, Tianjin, China, July 2018.

[27] D. Li and R. C. Soar, "Plastic flow and work hardening of Al alloy matrices during ultrasonic consolidation fibre embedding process," Materials Science and Engineering: A, vol. 498, no. 1-2, pp. 421-429, 2008.

[28] R. J. Friel and R. A. Harris, "A nanometre-scale fibre-tomatrix interface characterization of an ultrasonically consolidated metal matrix composite," Proceedings of the Institution of Mechanical Engineers, Part L: Journal of Materials: Design and Applications, vol. 224, no. 1, pp. 31-40, 2010.

[29] Y. Yang, G. D. Janaki Ram, and B. E. Stucker, "An experimental determination of optimum processing parameters for AlSiC metal matrix composites made using ultrasonic consolidation," Journal of Engineering Materials and Technology, vol. 129, no. 4, pp. 538-549, 2007.

[30] K. C. Joshi, "The formation of ultrasonic bonds between metals," Welding Journal, vol. 50, no. 12, pp. 840-848, 1971.

[31] J. J. Powers and J. B. Jones, "Ultrasonic welding," Welding Journal, vol. 35, no. 8, pp. 761-766, 1956.

[32] D. Li and R. Soar, "Influence of sonotrode texture on the performance of an ultrasonic consolidation machine and the interfacial bond strength," Journal of Materials Processing Technology, vol. 209, no. 4, pp. 1627-1634, 2009.

[33] C. Y. Kong, R. C. Soar, and P. M. Dickens, "Characterisation of aluminium alloy 6061 for the ultrasonic consolidation process," Materials Science and Engineering: A, vol. 363, no. 12, pp. 99-106, 2003.

[34] C. Y. Kong, R. C. Soar, and P. M. Dickens, "Optimum process parameters for ultrasonic consolidation of 3003 aluminium," Journal of Materials Processing Technology, vol. 146, no. 2, pp. 181-187, 2004.

[35] X.-H. He, H.-J. Shi, Y.-D. Zhang et al., "Mechanical properties and microstructure of $\mathrm{Al} / \mathrm{Al}$ laminated structure produced via ultrasonic consolidation process," Materials Science and Technology, vol. 31, no. 15, pp. 1910-1918, 2015.

[36] M. R. Sriraman, S. S. Babu, and M. Short, "Bonding characteristics during very high power ultrasonic additive manufacturing of copper," Scripta Materialia, vol. 62, no. 8, pp. 560-563, 2010.

[37] J. George and B. Stucker, "Fabrication of lightweight structural panels through ultrasonic consolidation," Virtual and Physical Prototyping, vol. 1, no. 4, pp. 227-241, 2006.

[38] R. J. Friel, K. E. Johnson, P. M. Dickens, and R. A. Harris, “The effect of interface topography for ultrasonic consolidation of 
aluminium," Materials Science and Engineering: A, vol. 527, no. 16-17, pp. 4474-4483, 2010.

[39] P. J. Wolcott, N. Sridharan, S. S. Babu, A. Miriyev, N. Frage, and M. J. Dapino, "Characterisation of Al-Ti dissimilar material joints fabricated using ultrasonic additive manufacturing," Science and Technology of Welding and Joining, vol. 21, no. 2, pp. 114-123, 2016.

[40] J. O. Obielodan, B. E. Stucker, E. Martinez et al., "Optimization of the shear strengths of ultrasonically consolidated Ti/ Al 3003 dual-material structures," Journal of Materials Processing Technology, vol. 211, no. 6, pp. 988-995, 2011.

[41] H. T. Fujii, M. R. Sriraman, and S. S. Babu, "Quantitative evaluation of bulk and interface microstructures in Al-3003 alloy builds made by very high power ultrasonic additive manufacturing," Metallurgical and Materials Transactions A, vol. 42, no. 13, pp. 4045-4055, 2011.

[42] T. Monaghan, A. J. Capel, S. D. Christie, R. A. Harris, and R. J. Friel, "Solid-state additive manufacturing for metallized optical fiber integration," Composites Part A: Applied Science and Manufacturing, vol. 76, pp. 181-193, 2015.

[43] Y. Yang, G. D. Janaki Ram, and B. E. Stucker, "An analytical energy model for metal foil deposition in ultrasonic consolidation," Rapid Prototyping Journal, vol. 16, no. 1, pp. $20-28,2010$.

[44] U. Khan, N. Z. Khan, and J. Gulati, "Ultrasonic welding of Bimetals: optimizing process parameters for maximum tensileshear strength and plasticity of welds," Procedia Engineering, vol. 173, pp. 1447-1454, 2017.

[45] C. Q. Zhang, J. D. Robson, O. Ciuca, and P. B. Prangnell, "Microstructural characterization and mechanical properties of high power ultrasonic spot welded aluminum alloy AA6111-TiAl6V4 dissimilar joints," Materials Characterization, vol. 97, pp. 83-91, 2014.

[46] K. E. Johnson, Interlaminar subgrain refinement in ultrasonic consolidation, Ph.D. thesis, Loughborough University, Leicestershire, UK, 2008.

[47] H. T. Fujii, S. Shimizu, Y. S. Sato, and H. Kokawa, "Highstrain-rate deformation in ultrasonic additive manufacturing," Scripta Materialia, vol. 135, pp. 125-129, 2017.

[48] A. Miriyev, A. Levy, S. Kalabukhov, and N. Frage, "Interface evolution and shear strength of $\mathrm{Al} / \mathrm{Ti}$ bi-metals processed by a spark plasma sintering (SPS) apparatus," Journal of Alloys and Compounds, vol. 678, pp. 329-336, 2016.

[49] M. Oghbaei and O. Mirzaee, "Microwave versus conventional sintering: a review of fundamentals, advantages and applications," Journal of Alloys and Compounds, vol. 494, no. 1-2, pp. 175-189, 2010.

[50] T. DebRoy, H. L. Wei, J. S. Zuback et al., "Additive manufacturing of metallic components-process, structure and properties," Progress in Materials Science, vol. 92, pp. 112-224, 2018.

[51] A. Gujba and M. Medraj, "Laser peening process and its impact on materials properties in comparison with shot peening and ultrasonic impact peening," Materials, vol. 7, no. 12, pp. 7925-7974, 2014.

[52] E. Uhlmann, C. Fleck, G. Gerlitzky, and F. Faltin, "Dynamical fatigue behavior of additive manufactured products for a fundamental life cycle approach," Procedia CIRP, vol. 61, pp. 588-593, 2017.

[53] N. Sridharan, M. N. Gussev, C. M. Parish et al., "Evaluation of microstructure stability at the interfaces of Al6061 welds fabricated using ultrasonic additive manufacturing," Materials Characterization, vol. 139, pp. 249-258, 2018.
[54] N. Al-Aqeeli, K. Abdullahi, A. S. Hakeem, C. Suryanarayana, T. Laoui, and S. Nouari, "Synthesis, characterisation and mechanical properties of $\mathrm{SiC}$ reinforced $\mathrm{Al}$ based nanocomposites processed by MA and SPS," Powder Metallurgy, vol. 56, no. 2, pp. 149-157, 2013.

[55] N. Al-Aqeeli, K. Abdullahi, and C. Suryanarayana, "Structure of mechanically milled CNT-reinforced Al-alloy nanocomposites," Materials and Manufacturing Processes, vol. 28, no. 9, pp. 984-990, 2013.

[56] M. R. Sriraman, M. Gonser, D. Foster, H. T. Fujii, S. S. Babu, and M. Bloss, "Thermal transients during processing of materials by very high-power ultrasonic additive manufacturing," Metallurgical and Materials Transactions B, vol. 43, no. 1, pp. 133-144, 2012.

[57] K. Sojiphan, M. R. Sriraman, and S. S. Babu, "Stability of microstructure in $\mathrm{Al} 3003$ builds made by very high power ultrasonic additive manufacturing," in Proceedings of the 21st International Solid Freeform Fabrication Symposium, vol. 22, no. 2, pp. 362-371, Austin, TX, USA, 2010.

[58] C. Zhang, A. Deceuster, and L. Li, "A method for bond strength evaluation for laminated structures with application to ultrasonic consolidation," Journal of Materials Engineering and Performance, vol. 18, no. 8, pp. 1124-1132, 2009.

[59] K. Abdullahi and N. Al-Aqeeli, "Mechanical alloying and spark plasma sintering of nano-SiC reinforced Al-12Si-0.3Mg alloy," Arabian Journal for Science and Engineering, vol. 39, no. 4, pp. 3161-3168, 2014.

[60] R. Hahnlen and M. J. Dapino, "NiTi-Al interface strength in ultrasonic additive manufacturing composites," Composites Part B: Engineering, vol. 59, pp. 101-108, 2014.

[61] M. R. Rezaei, M. R. Toroghinejad, and F. Ashrafizadeh, "Effects of ARB and ageing processes on mechanical properties and microstructure of 6061 aluminum alloy," Journal of Materials Processing Technology, vol. 211, no. 6, pp. 11841190, 2011.

[62] A. B. Spierings, T. L. Starr, and K. Wegener, "Fatigue performance of additive manufactured metallic parts," Rapid Prototyping Journal, vol. 19, no. 2, pp. 88-94, 2013.

[63] A. S. Johnson, S. Shao, N. Shamsaei, S. M. Thompson, and L. Bian, "Microstructure, fatigue behavior and failure mechanisms of direct laser deposited inconel 718," The Journal of the Minerals, Metals \& Materials Society, vol. 69, no. 3, pp. 499-511, 2016.

[64] E. Amsterdam and G. A. Cool, "High cycle fatigue of laser beam deposited Ti-6Al-4V and Inconel 718," in Bridging the Gap between Theory and Operational Practice, pp. 1261-1274, Springer, Rotterdam, Netherlands, 2009.

[65] A. J. Sterling, B. Torries, N. Shamsaei, S. M. Thompson, and D. W. Seely, "Fatigue behavior and failure mechanisms of direct laser deposited Ti-6Al-4V," Materials Science and Engineering: A, vol. 655, pp. 100-112, 2016.

[66] X.-F. Ma, Z. Duan, H.-J. Shi, R. Murai, and E. Yanagisawa, "Fatigue and fracture behavior of nickel-based superalloy inconel 718 up to the very high cycle regime," Journal of Zhejiang University-Science A, vol. 11, no. 10, pp. 727-737, 2010.

[67] A. Fatemi, R. Molaei, S. Sharifimehr, N. Phan, and N. Shamsaei, "Multiaxial fatigue behavior of wrought and additive manufactured Ti-6Al-4V including surface finish effect," International Journal of Fatigue, vol. 100, pp. 347-366, 2017.

[68] D. Greitemeier, F. Palm, F. Syassen, and T. Melz, "Fatigue performance of additive manufactured TiAl6V4 using 
electron and laser beam melting," International Journal of Fatigue, vol. 94, pp. 211-217, 2017.

[69] A. W. Prabhu, T. Vincent, A. Chaudhary, W. Zhang, and S. S. Babu, "Effect of microstructure and defects on fatigue behaviour of directed energy deposited Ti-6Al-4V," Science and Technology of Welding and Joining, vol. 20, no. 8, pp. 659-669, 2015.

[70] A. Bača, R. Konečná, G. Nicoletto, and L. Kunz, "Influence of build direction on the fatigue behaviour of ti6al4v alloy produced by direct metal laser sintering," Materials Today: Proceedings, vol. 3, no. 4, pp. 921-924, 2016.

[71] X.-H. He, H.-J. Shi, Y.-D. Zhang, W.-X. Fu, Z.-G. Yang, and C. E. Wilkinson, "In-situ scanning electron microscopy studies of small fatigue crack growth in ultrasonic consolidation bonded aluminum 2024 laminated structure," Materials Letters, vol. 112, pp. 47-50, 2013.

[72] P. J. Wolcott and M. J. Dapino, Fatigue Characterization of Ultrasonic Additive Manufactured, Department of Mechanical and Aerospace Engnieering, The Ohio State University, Columbus, OH, USA, 2012.

[73] X. C. Zhang, Y. K. Zhang, J. Z. Lu, F. Z. Xuan, Z. D. Wang, and S. T. Tu, "Improvement of fatigue life of Ti-6Al-4V alloy by laser shock peening," Materials Science and Engineering: A, vol. 527, no. 15, pp. 3411-3415, 2010.

[74] M. Y. P Costa, H. J. C Voorwald, W. L. Pigatin, V. A. Guimarães, and M. O. H. Cioffi, "Evaluation of shot peening on the fatigue strength of anodized Ti-6Al-4V alloy," Materials Research, vol. 9, no. 1, pp. 107-109, 2006.

[75] A. Galtier and E. S. Statnikov, "The influence of ultrasonic impact treatment on fatigue behaviour of welded joints in high-strength steel," Welding in the World, vol. 48, no. 5-6, pp. 61-66, 2004.

[76] A. Cherif, Y. Pyoun, and B. Scholtes, "Effects of ultrasonic nanocrystal surface modification (UNSM) on residual stress state and fatigue strength of AISI 304," Journal of Materials Engineering and Performance, vol. 19, no. 2, pp. 282-286, 2009.

[77] P. S. Prevéy and J. T. Cammett, "The influence of surface enhancement by low plasticity burnishing on the corrosion fatigue performance of AA7075-T6," International Journal of Fatigue, vol. 26, no. 9, pp. 975-982, 2004.

[78] A. K. Gujba, Z. Ren, Y. Dong, C. Ye, and M. Medraj, "Effect of ultrasonic nanocrystalline surface modification on the water droplet erosion performance of Ti-6Al-4V," Surface and Coatings Technology, vol. 307, pp. 157-170, 2016.

[79] Y.-L. Kuo, S. Horikawa, and K. Kakehi, "Effects of build direction and heat treatment on creep properties of Ni-base superalloy built up by additive manufacturing," Scripta Materialia, vol. 129, pp. 74-78, 2017.

[80] H. Y. Song, Multi-scale microstructure characterization for improved understanding of microstructure-property relationship in additive manufacturing, Ph.D. thesis, The Ohio State University, Columbus, OH, USA, 2016.

[81] L. Rickenbacher, T. Etter, S. Hovel, and K. Wegener, "High temperature material properties of IN738LC processed by selective laser melting (SLM) technology," Rapid Prototyping Journal, vol. 19, no. 4, pp. 282-290, 2013.

[82] K. Kunze, T. Etter, J. Grässlin, and V. Shklover, "Texture, anisotropy in microstructure and mechanical properties of IN738LC alloy processed by selective laser melting (SLM)," Materials Science \& Engineering A, vol. 620, pp. 213-222, 2015.

[83] M. Pröbstle, S. Neumeier, J. Hopfenmüller et al., "Superior creep strength of a nickel-based superalloy produced by selective laser melting," Materials Science and Engineering: A, vol. 674, pp. 299-307, 2016. 